\title{
LA PRESENCIA Y OCASO DE LOS CACICAZGOS TupíEs de la Cuenca del Alto Amazonas EN LOS SIGLOS XVI Y XVII
}

\author{
JAIME REGAN
}

Este estudio es una lectura comparativa de las crónicas de los siglos XVI y XVII sobre los omaguas, los cocamas y los mainas y cipitaconas en el Perú. Vislumbra poblaciones grandes de miles de personas con un manejo de tecnología para las tierras inundables en cuanto a la agricultura, la pesca, la caza de animales acuáticos, y abundantes alimentos con técnicas para su almacenaje. Estaban estructurados en cacicazgos que organizaban comercio a larga distancia y guerra, y gobernados por jefes hereditarios muy respetados. Con la llegada de las enfermedades epidémicas y pandémicas europeas y la esclavitud, todo esto empezó a desplomarse. ${ }^{1}$

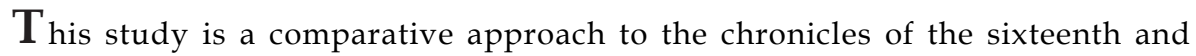
seventeenth centuries that deal with the Omaguas, the Cocamas and the Mainas and Cipitaconas in Peru. It envisions large populations with thousands of people who managed technology for the Amazon floodplain in agriculture, fishing, hunting of aquatic animals, with abundant food and techniques for its storage. They were formed into chiefdoms which organized long-distance trade and warfare, and were governed by respected hereditary leaders. With the arrival of the European epidemic and pandemic diseases and slavery, all this began to fall apart.

Alexander Aquituari Ahuanari, cocama de Nauta y estudiante de antropología en la Universidad Nacional Mayor de San Marcos en Lima, leyó muchas partes de este texto e hizo aportes valiosos. 
Durante los últimos cuarenta años se han ido perfilando las características de los cacicazgos amazónicos (Evans and Meggers 1968; Carneiro 1970; Lathrap 1970; Meggers 1971; Roosevelt 1980, 1987, 1991). Los primeros europeos que viajaron por el Amazonas encontraron pueblos grandes y bien organizados en cacicazgos en la llanura de inundación (várzea), a diferencia de las sociedades del interior (tierra firme). El cacicazgo es un nivel de evolución política más compleja que la comunidad acéfala y menos complejo que el Estado burocrático, «una unidad política autónoma consistiendo en un número de caseríos bajo el control permanente de un jefe principal» (Carneiro 1981: 45). Los cacicazgos se han encontrado en muchos lugares del mundo antes de la difusión del Estado burocrático y han variado mucho en sus características específicas y los atributos de los caciques.

En su obra clásica Amazonia, Hombre y Cultura en un Paraíso Ilusorio (1971; 1981), Betty Meggers aplicó el método comparativo para estudiar la adaptación de los pueblos a la tierra firma (área no inundable) de pueblos existentes en el siglo veinte y a la várzea (llanura de inundación) de pueblos de los siglos dieciséis y diecisiete, los cacicazgos de los omaguas y los tapajós, en lo que ahora es el territorio brasileño.

Para servir de contexto para muchos de los estudios arqueológicos de este número de Amazonía Peruana, se examinan los cacicazgos que ocupaban las tierras inundables en los siglos XVI y XVII en lo que ahora es el Perú, retomando los datos sobre los omaguas ${ }^{2}$ para compararlos con los de los cocamas y los mainas y cipitaconas, de afiliación tupí. Probablemente había otros cacicazgos, como los antepasados de los shipibo-conibos (pano) y yines o piros (arawak)

Cabe señalar que la nomenclatura de los ríos principales varía entre el Perú y Brasil. Según los mapas peruanos el río Amazonas comienza donde se unen los ríos Marañón y Ucayali. El término «Alto Amazonas» refiere al territorio aguas arriba del los ríos Negro y Madeira. En Brasil esta parte del río se llama Solimoes hasta la frontera con el Perú y Marañón al lado peruano.

\section{La Llanura de Inundación}

Para entender la dinámica de los pueblos amazónicos antiguos y actuales, es importante tener en cuenta la distinción que hace Betty Meggers (1981) entre la várzea (llanura de inundación) y la tierra firme (tierras no inundables). En el Perú existen actualmente sociedades indígenas en ambas áreas que pueden iluminar el debate sobre los pueblos antiguos.

Las estaciones en la llanura de inundación dependen de la subida y bajada del nivel de los ríos. En el bajo Marañón la creciente máxima de los ríos que vienen

Actualmente se pronuncia y se escribe «umawa», y «kukama», pero en este texto se sigue la forma que usan los documentos antiguos. 
del sur ocurre entre octubre y abril y en los ríos que desembocan en el norte entre abril y agosto (Meggers 1981:24-25). Según la misma autora, los sedimentos depositados en la várzea con la merma del río en Brasil en una hectárea son ocho toneladas por año.

[...] contienen generosas cantidades de nitrato de sodio, carbonato de calcio, sulfato de magnesio, fosfatos, cloruro de potasio y otros nutrientes esenciales para las plantas (ibid.:50).

Un Seminario reciente realizado en Iquitos (IIAP 2007) ha presentado información precisa sobre la llanura de inundación. Esta área no es uniforme, sino que tiene varios nichos ecológicos. En primer lugar, el tipo de agua es un factor importante. Los ríos de aguas blancas tienen su origen en los Andes y contienen arena, arcilla y limo de un alto valor $\mathrm{pH}$ con los elementos indicados arriba por Meggers. Son lugares muy aptos para la vida acuática y los cultivos. En cambio, los ríos de aguas negras, que tienen su origen en la selva, tienen valores de $\mathrm{pH}$ ácidos, y tienen menos oxígeno (IIAP 2007: 7).

Las playas son las áreas más cercanas al río y son de arena fina. Durante el estiaje siembran en este lugar frijol caupi, chiclayo, melón, zapallo, sandía, tomate, culantro y maní. Los barriales, que se ubican adyacentes a las playas, contienen limo y arcilla donde actualmente se siembra arroz y sandía. Las restingas son zonas formadas por sedimentos depositados en distintas inundaciones, que son más elevadas que las playas y barreales. Las restingas bajas tienen inundaciones de hasta un metro sobre el suelo, las restingas medias tienen menos de un metro de agua durante las inundaciones, y las restingas altas se inundan cada dos a siete años. En las restingas bajas y medias los cultivos principales son variedades de yuca y maíz que se pueden cosechar en tres meses, frijol y hortalizas. En las restingas altas se encuentran las viviendas, el cultivo de plátano y yuca y la crianza de cerdos, patos y gallinas. Las restingas también son el refugio para varias especies de animales terrestres y aves (ibid.: 2-3, 6-7). Además del manejo de las áreas de inundación, muchos tienen sus casas en las barrancas sobre los ríos principales y cultivan yuca y plátanos en áreas de tierra firme.

Las islas son depósitos de sedimentos rodeados de agua donde se encuentran los distintos nichos ecológicos de inundación y son lugares preferidos de vivienda y cultivo para los cocamas. Los bajiales están ubicados entre dos restingas o entre una playa y una restinga donde hay un mal drenaje. Llevan nombres por el tipo de vegetación que contienen, por ejemplo, gramalotal, renacal, etc. Las cochas son lagunas, antiguos recodos del río, que se quedan alejados del cauce principal del río por el depósito de sedimentos (ibid.: 6-7).

Las tahuampas son pantanos formados por antiguos cursos de los ríos y están permanentemente cubiertos de agua. Contienen una diversidad de hierbas, arbustos 
y árboles y son lugares de anidación de aves acuáticas y de alimentación para peces. Los aguajales son lugares de drenaje muy bajo en aguas negras donde predomina la palmera aguaje, cuyo fruto sirve de alimento de varias especies de animales (ibid.) y los seres humanos. También se encuentran algunas especies de peces como curhuara, shuyo, gamitana, paco.

Actualmente 440,000 personas viven en la llanura de inundación de la Amazonía peruana y proporcionan pescado para su propio sustento y para el sustento de 850,000 personas que viven en las ciudades de la tierra firme (IIAP 2007: 1). La llanura fluvial del departamento de Loreto provee entre 60,000 y 80,000 toneladas de pescado al año que es el $40 \%$ de la proteína que consumen los pobladores de las ciudades locales, y para los cocamas y otros ribereños, es el 80\% (ibid.: 2).

Los bosques inundables son lugares de una gran diversidad de actividades:

caza de subsistencia, extracción de frutos, lianas, bejucos, miel, hojas de palmeras, flores, cortezas, brotes, yemas, fibras, látex, resinas, gomas, maderas, huevos de tortuga, pesca ornamental y plantas ornamentales. Un gran porcentaje de la actividad maderable de la región se sustenta de especies provenientes de la llanura de inundación, como la lupuna, cedro, capirona, cumala y capinuri (ibid).

Florecieron sociedades grandes en la llanura de inundación, no sólo en el curso bajo del Amazonas (Meggers 1971; Roosevelt 1993), sino también en el Alto Amazonas. Este trabajo se centra en esta región menos estudiada, donde había una significativa dinámica cultural durante miles de años antes de la llegada de los europeos.

Es difícil calcular la población en aquellos años por la falta de datos precisos. Sin embargo, los cronistas unánimemente concuerdan que había poblaciones muy grandes y densas a lo largo de las riberas de los ríos grandes, y muchos de estos viajeros no llegaron a ver lo que había en las tierras inundables del interior. El estimado de Denevan (1980) es de seis millones para toda la Amazonía. Myers (1988) estima que había más, sólo entre los omaguas y cocamas, tres millones. Las epidemias y pandemias de enfermedades de origen europeo redujeron drásticamente la población, muchas veces matando a más del ochenta \% cada vez. Los datos de población presentados arriba dan una idea de la capacidad de sustento de la llanura de inundación en el Perú (IIAP 2007).

Hoy en día la situación de vida en la llanura de inundación está en peligro por la contaminación de basura, derrames de petróleo, depredación de especies acuáticas, y el uso de insecticidas químicos que afectan a los peces que se alimentan en los arrozales como la cahuara, lisa y bagre. El estudio de los pueblos antiguos, el manejo de sus paisajes y lo que queda de las tecnologías antiguas pueden aportar a la supervivencia de futuras poblaciones en la Amazonía. 


\section{Los Tupinambás}

Antes de presentar a los cacicazgos escogidos, es relevante señalar la presencia de tupinambás en el Alto Amazonas a mediados del siglo XVI. A partir del año 1538 varios miles de guerreros tupinambás (brasiles) con sus familias, en 1500 canoas, emprendieron viaje desde su territorio tradicional en la costa del Atlántico de Brasil y entraron en el río Amazonas, bajo la dirección del cacique Viarazú ${ }^{3}$.

El portugués Diego de Nunes y un grupo de soldados, enviado por Alonso de Mercadillo a explorar el Amazonas en 1538, podrían haberse contagiado de una enfermedad porque Mercadillo se había enfermado en la boca del Huallaga. Nunes (1993) escribió una carta al rey de Portugal Don Joao III en 1553, que relata su visita al territorio de los omaguas y al cacique Machifalo. Habló de pueblos ricos en oro y que tenían mucho maíz, yuca y que vendían pescado seco a otros pueblos. También dio noticia de los 300 tupinambás que llegaron a Chachapoyas:

[...] hallamos buena tierra y bien poblada de indios y rica en oro según lo que veía y según los indios nos indicaban, que bien parecía una tierra abundante en oro, porque los indios tenían armas y brazaletes de oro en los brazos [...]. Esta provincia donde yo llegué se llama Machifalo[...]. Traje conmigo ciertos indios de estas provincias, de quienes me informé de lo que había adelante (de Machifalo). Uno de estos indios tuve en mi compañía 14 o 15 años.

Después que salimos de esta tierra vimos detrás de nosotros 14 mil indios que querían saber qué gente éramos, y en el camino encontramos a otros indios de otro señor con quienes tenian guerra y estos los mataron a todos que no dejaron más que 300 vivos, los cuales se fueron fugando por un río en unas canoas y a cabo de cierto tiempo fueron a un pueblo de cristianos que hay en el Perú que se llama las Chachapoyas.

Habrá en este camino por donde se fueron los indios al Perú 500 leguas*. Y estos indios se reconocieron a los otros que yo traje, porque eran todos de una tierra y de un señor. Y la relación de la tierra que yo había conocido a mis indios y los que estos me dijeron era una sola. Y estos 300 indios viven ahora en el Perú.

El cronista del viaje de Ursúa, Francisco de Vázquez, en 1560 (1988: 26) relató algo similar.

Estos indios brasiles salieron de sus tierras, que son en la costa del Brasil, más de diez o doce mil de ellos, en muchas canoas, con sus mujeres e hijos, y con dos españoles

\footnotetext{
3 Es posible que este nombre proceda de la palabra «yara» que significa «dueño, jefe, cacique». El sufijo -zú, o -wazú es aumentativo. Entonces el nombre Viarazú significaría «gran cacique» (Alexander Aquituari Ahuanari, cocama: comunicación personal)

* La distancia que se podía viajar en una hora.
} 
portugueses, y el uno decían que llamaba Mateo, a buscar mejor tierra que la suya (...). Tardaron en subir el Pirú por este dicho río más de diez años, y de los doce mil indios solamente llegaron hasta trescientos, con algunas mujeres, y vinieron a dar a un pueblo que se dice Chachapoyas, y ahí se quedaron entre los españoles.

Los que llegaron al Perú hablaron de las grandes cosas que habían visto en su viaje, sobre todo de la provincia de Omagua, la muchedumbre de gente que había visto y la abundancia de oro y plata (ibid.: 27), y los españoles querían tomarlos como esclavos. Los españoles llevaron a Viarazú y cinco o seis indios a Lima para entrevistarse con el virrey, quien encargó a Pedro de Ursúa la conquista de este territorio. Luego el Rey y su Consejo de las Indias, al conocer el intento de esclavizar a estos indios, recordaron a la Audiencia de los Reyes (en Lima) la ley que prohibía la esclavitud de los indios (Jiménez de la Espada 1965: 239).

El cronista Pedro de Cieza de León (1973: capítulo LXXIX) habla de este acontecimiento.

En el año del Señor de 1550 años llegaron a la ciudad de la Frontera (siendo en ella corregidor el noble caballero Gómez de Albarado) más de doscientos indios, los cuales contaron que hacía algunos años que, saliendo de la tierra donde vivían número grande de gente de ellos, atravesaron por muchas partes y provincias, y que tanta guerra les dieron, que faltaron todos, sin quedar más de los que dije. Los cuales afirman que a la parte del levante hay grandes tierras, pobladas de mucha gente, y algunas muy ricas de metales de oro y plata; y estos, con los demás que murieron, salieron a buscar tierras para poblar, según oí.

Un motivo de viajar podría haber sido escaparse de epidemias en la costa de Brasil (Cook 1998: 148-149).

El cacique Virarazú parece haber sido la cabeza de un movimiento profético del tipo que han surgido varias veces en la región en los últimos cinco siglos (véase Métraux 1973: 3-34). En la Historia da Provincia Santa Cruz que Vulgarmente Chamamos Brasil de Pedro de Maglhaes de Gandavo (citado en Jiménez de la Espada 1965, IV: 236), refiriendo a este viaje, habla de la búsqueda de un lugar terrenal donde se puede alcanzar la inmortalidad. El texto citado menciona que «algunos pocos» se alzaron. Es una expresión muy relativa pero indicaría que los que se alzaron habrían formado parte una enorme muchedumbre.

[...] (los indios) como carezcan de haciendas que los retengan en su patria, y sea su constante deseo de buscar tierras nuevas, por parecerles que hallarán en ellas inmortalidad y descanso perpetuo, aconteció como algunos pocos se alzaron de las suyas y se internaron en el monte [...].

No se sabe donde exactamente se asentaron los tupinambás, además de Chachapoyas o Moyobamba, pero algunos podrían haberse asentado más abajo del río 
Pastaza (Sumatara), al margen derecho del Marañón. El escribano Cristóbal de Saavedra (1965: 244), escribiendo en 1619, habla del cacique Viaro, que podría ser Viarazú.

Desde la entrada de este río de Sumatara se ha de caminar en el Marañón, caminando por él abajo cuatro leguas, a la mano derecha, hay otro río que llaman los indios Cachumaga, y los antiguos le pusieron Viaro, por el cacique Viaro que estaba en él. Hay noticia que está poblado de gente.

\section{Fuentes Bibliográficas Antiguas}

Los arqueólogos dependen de evidencia indirecta para reconocer los cacicazgos, fijándose sobre todo en cerámica suntuosamente elaborada supuestamente por especialistas y otras evidencias materiales (Carneiro 1995:55). Los documentos escritos de los siglos XVI y XVII nos dan mayores detalles de la vida y organización de estos pueblos. Anna Roosevelt (1993) ha publicado una síntesis de la dinámica de los cacicazgos del bajo Amazonas: «The Rise and Fall of the Amazon Chiefdoms», y Thomas Myers (1992) sobre los omaguas: «The Expansion and Collapse of the Omagua».

En este estudio, se usan fuentes antiguas cuando están disponibles, aunque sean ediciones posteriores. Por lo tanto, indico el año de los hechos descritos y/o de la publicación original para los autores más consultados. Entre paréntesis se indica el año de la edición usada y citada en la bibliografía.

1538 Diego de Nunes, soldado portugués (1553)

1542 Gaspar de Carvajal, cronista dominico español (1942)

1553 Pedro de Cieza de León, cronista real español (1973)

1558 Juan de Salinas Loyola, militar español (1965)

1560 Francisco de Vázquez, militar y cronista español (1988)

1574 Juan López de Velasco, geógrafo español (1971)

1619 Cristóbal de Saavedra, escribano público español (1965)

1639 Cristóbal de Acuña, cronista real jesuita español (1986)

1653 Laureano De la Cruz, misionero franciscano (1999)

1661 Francisco de Figueroa, misionero jesuita criollo (1986)

1681 Lorenzo Lucero, misionero jesuita español (1986)

1689 Pedro de Mercado, historiador jesuita criollo (1957)

1702 Samuel Fritz, misionero y cartógrafo jesuita bohemio (1988)

1738 Pablo Maroni, misionero jesuita italiano (1988)

1741 Jean Magnin, misionero jesuita suizo (1998)

1768 Francisco Xavier Veigl, misionero jesuita austríaco (2006)

1770 José Chantre y Herrera, historiador jesuita español (1901)

Cuando llegaron los tupinambás al Perú en 1550, había otras sociedades que aparentemente hablaban una lengua relacionada al tupinambá y que ocupaban las 
riberas inundables. Los descendientes de algunos de estos pueblos, aunque hayan perdido su organización política antigua, actualmente conservan la tecnología adaptada a llanura de inundación y su cosmovisión, además de lo que han adquirido de otras fuentes. En los últimos cincuenta años los omaguas y cocamas han estado perdiendo sus idiomas, y su sistema de parentesco está debilitándose. Para un conocimiento de la adaptación a este ecosistema contamos con varios estudios etnográficos de los cocama-cocamillas ${ }^{4}$ y omaguas de cultura tupí y otro ribereños: Tessmann 1999 [original 1930]; Espinosa 1935; Girard 1958b; Stocks 1981; Regan 1983; Agüero 1994; Chibnik 1994; Rivas 2003a, 2003b, 2004.

A continuación se compararán los documentos existentes para comprender mejor la realidad de los pueblos de cultura tupí de la llanura de inundación del Perú durante los siglos XVI y XVII: los omaguas, los cocamas y los mainas y cipitaconas. Compartían varias características: 1) lengua, 2) adaptación a las riberas inundables, asentamiento y transporte, 3) armas 4) subsistencia, 5) vestimenta y cerámica, 6) deformación del cráneo, 7) organización social y política. El conjunto de variables permite vislumbrar una cultura común en la llanura de inundación, que se distinguía de la de los grupos del interior.

\section{LOS OMAGUAS}

Existe evidencia de la presencia de omaguas en el río Napo desde el siglo XII. Hay tres fechados $C_{14}: 1168 \pm 53$ d.C., $1179 \pm 51$ d.C. $y 1480 \pm 180$ d.C. (Evans and Meggers 1968: 81). Lathrap (1970: 151) dice que la Fase Napo en el río Napo y sus afluentes Aguarico y Tiputini en Ecuador duró entre 1100 y 1700 d.C. Jijón y Caamaño (1997: 344) describió la aparición de una civilización en el Alto Napo distinta de las de la Sierra y Costa ecuatorianas.

En el Alto Napo, cerca de la confluencia del Curaray, aparece una civilización completamente distinta de las de la Sierra y Costa ecuatorianas [...]. Esta cultura se vincula a las de Marajó, Moxos y Santarem, si bien tiene más estrecha afinidad con la primera.

Probablemente era el resultado de una migración desde el Amazonas central en lo que ahora es Brasil (Lathrap 1970:155). Las primeras descripciones escritas de los omaguas en el Amazonas son de Diego de Nunes (1993) en 1538, Gaspar de Carvajal (1942) en 1542 y Francisco de Vázquez (1988) en 1560.

Una investigación hecha en Google Earth (Mora s.f.) ha precisado la ruta seguida por la expedición de Orellana en 1542, mostrando que no había bajado por el río Napo sino por el Putumayo. Los viajeros no tenían una idea precisa de dónde estaban. La trayectoria del viaje estaba demasiado larga para que tuviera lugar en el Napo. Además, el cronista Gaspar de Carvajal había dado el nombre de Trinidad al

Actualmente se habla y se escribe «kukamiria». 
río con el cual se juntaba el río donde navegaba, porque había tres islas, que correspondería a la boca del Putumayo. Entonces habría encontrado a los omaguas más abajo de la desembocadura del Putumayo y que se extendía más de cien leguas, entre el Japurá y el Coarí en 1542 (cf. Meggers 1981: 180).

Esta ubicación antigua de los omaguas aclara la discrepancia que Métraux (1963 III: 689) encontró entre Carvajal y otros cronistas. Carvajal colocó a los omaguas más debajo de la desembocadura del río que había navegado, y no a partir del Napo porque no habría conocido este tramo.

La expedición de Orellana pasó por el territorio de los Omagua, pero su cronista, Carvajal, da el nombre Omagua a una tribu ubicada más abajo del Río Trinidad (probablemente el Río Juruá) ${ }^{5}$, i.e. al este del territorio de los Omagua definido por viajeros posteriores. Según estas fuentes, el país de los Omagua empezó en la boca del Río Napo y se extendía al este hasta la desembocadura del Río Jutahy en el Amazonas [...]. Entonces, los Omagua de Carvajal probablemente no eran los Omagua históricos, sino que deben identificarse con los Indios gobernados por Aparia el Grande y tal vez por Machifaro.

Este descubrimiento en Google también ayudaría a entender algo que ocurrió en el viaje de Ursúa. Uno de los participantes en el viaje de Orellana aparentemente no conocía el trayecto entre el Napo y el Putumayo.

Iba con nosotros un español de los que habían bajado por el río con Orellana, el cual no conocía la tierra, y desatinaba [...] (Vázquez 1988: 42).

Pedro de Ursua también llevó algunos de los tupinambás como intérpretes y guías de su expedición (ibid.: 31) y 40 hombres de la expedición de Salinas. En este viaje, entonces, participaron miembros de cada uno de los tres viajes anteriores: los de Orellana, Viarazú y Salinas de Loyola.

No tenemos cifras sobre la totalidad de la población de los omaguas antes de la llegada de los europeos, pero podría haber sido más de cien mil personas. Como explica Myers (1992), desde la llegada de los europeos, hubo varias epidemias que diezmaron la población.

Los padres Acuña (1986: 72) y De la Cruz (1999: 358) a mediados del siglo XVII coinciden en la longitud del territorio de los omaguas, 200 leguas. Las diferencias entre Carvajal y estos dos en cuanto al tamaño del territorio omagua sería el tramo más arriba del Putumayo, además de los cien años recorridos. Las medidas de De la Cruz dan la cifra de 4.8 kilómetros por legua ${ }^{6}$. Entonces los omaguas habrían ocupado tierras a lo largo de 960 kilómetros, con poblaciones «tan a menudo, que apenas se

\footnotetext{
El Río Trinidad probablemente era el Amazonas en la unión con el Putumayo.
}

Véase Villarejo 1988: 80. 
pierde una de vista, cuando ya se descubre otra», según Acuña (1986: 72) en 1640. Después de una epidemia severa, De la Cruz (1999: 358) en 1648 dijo «Pues en 200 leguas de largo que tienen en los omaguas con 34 pueblos pequeños, no hallamos 1,000 indios cabales fuera de sus mujeres y muchachos, que no son muchos [...]».

De la Cruz (1999: 355-356) describe la peste de 1648.

Llegó a nuestro pueblo de Caraute la peste río abajo, y el día siguiente amanecieron heridos de ella un mozuelo y una india vieja, en casas diferentes; y de estos dos se fue cundiendo y pegando en los demás, de tal suerte que en mucho más de un mes no quedó en todo el lugarcito persona grande ni pequeña que no cayese miserablemente (...) pasáronlo tan desdichadamente que murieron muchos.

Además de la región ubicada en el mismo Napo y río abajo del Napo, Saavedra (1965: 244) dice que se encontraban omaguas en el río Tigre:

Desde este río Mani, caminando el Marañón abajo cuatro días, se va al de Omaguas, que también viene de tierra de Macas, a mano izquierda; y se tiene noticia que está poblado de mucha gente Omagua y de otras provincias que confinan con Macas y Quito.

De la Cruz también habla de la presencia de omaguas en este lugar.

Júntanse con el río Marañón el río de los Jívaros, el de los Maguas (sic) y otros antes de entrar en el nuestro. Entre estas juntas de estos ríos está una provincia de infieles que se llaman Aguanatios, y son también Omaguas de cabezas chatas. Setenta leguas más abajo de estas juntas está la provincia de los Omaguas (De la Cruz 1999: 350).

Con la ayuda de los misioneros jesuitas, los omaguas se trasladaron más al occidente para escaparse de los esclavistas portugueses, y finalmente la comunidad de San Joaquín de Omaguas quedó en el margen izquierdo del Marañón cerca de la desembocadura del Ucayali.

\section{1) Lengua}

Las apreciaciones y clasificaciones de lenguas que hacen los autores antiguos no tienen sustentos lingüísticos, pero nos pueden dar indicaciones para identificar las relaciones entre algunos pueblos. Dado el gran número de idiomas hablados en

El geógrafo Marcos Jiménez de la Espada (1965: 244) lo identifica como el río Tigre. También dice que se llamaba Amapiaga o Piquiena.

$8 \quad$ De la Cruz (1999: 350) dice que la distancia entre el río Curaray y la boca del Napo son 80 leguas o 225.5 millas (Villarejo 1988: 260) y entre el río Omaguas y la boca del Napo son 70 leguas o 197 millas. Usando la medida de Laureano De la Cruz, 4.8 kilómetros por legua, se confirma que se trata de la zona entre el río Tigre y el Chambira. 
la región, muchos indígenas hablaban más de uno, y los viajeros de habla castellana los llevaban como intérpretes y guías.

Los antiguos misioneros jesuitas relacionaban el idioma omagua con el tupinambá, basándose probablemente en el vocabulario.

Esta lengua Omagua tengo por cierto que, según su primera (sic) origen, no es otra que la de los Tupinambas que vinieron del Brasil, donde cerca de la Baja [de Todos os Santos] hay aun muchos de ellos; y esta es la lengua que los portugueses del Pará y Brasil llaman «lengua general», y en la realidad no hay otra que tanto se entienda como esta. Desde Napo, Marañón para arriba, a más de los Omaguas, la hablan los Cocamas de Ucayale, y según se dirá hablando de esta nación, aun cerca de Santiago de las Montañas, más arriba de Borja, los Xibitinoas usaba de esta lengua; para no hablar de los Omaguas que viven arriba de Napo. Los portugueses llaman esta lengua también «lengua de los Caboclos», indios los más antiguos del Brasil, de quienes dicen que la aprendieron los Tupinambas. Aun en el Paraguay discurro hay vestigios de esta lengua (Maroni 1988: 169).

La principal y más numerosa de estas naciones, a quien antiguamente temían mucho los demás, es la de los Omaguas, oriundos probablemente de los Tupinambas del Brasil, como da a entender su idioma, que poco se diferencia del que los portugueses llaman Lengua general o de los Tupinambas, y según dicen, se extiende a muchas naciones del Brasil (Fritz 1988: 304).

De esta última lengua de los Omaguas dudaban los misioneros si era matriz o hija de la famosa lengua del Brasil o de la célebre Guaraní del Paraguay, con las cuales tiene tanta hermandad o semejanza, que un padre que pasó de Omaguas al Brasil, trataba por medio de ella con aquellos indios y entendía las doctrinas que tenían impresas en su lengua; y lo mismo le sucedió con los misioneros de Guaraníes, cuando hablaban en lengua Guaraní (Chantre y Herrera 1901: 93).

En la misión de San Joaquín de Omaguas aprendían el quichua como lengua general (Maroni 1988: 373-374) gente de varios lugares que hablaban distintos idiomas. Sin embargo, el omagua iba imponiéndose como lengua general.

Aun mayor es la dificultad que se experimenta para introducir la lengua del Inga en las nuevas reducciones que se van al presente formando, por la poca comunicación que tienen los indios de esta lengua. En estas reducciones, principalmente en la de los Yameos y Caumaris, aun con más facilidad que la del Inga parece se va introduciendo la lengua de los Omaguas, no sólo por ser más fácil y menos gutural que otras del Marañón, sino también por ser hoy día la reducción de San Joaquín como cabeza y seminario de las nuevas naciones y el real de donde se sale a las conquistas (Maroni 1988: 169). 


\section{2) Asentamiento, Adaptación a la Llanura de Inundación y Transporte}

En el siglo XVI los asentamientos vistos por los europeos se encontraban en las orillas del río. En los viajes de Orellana y Ursúa la legua era dos kilómetros (véase Mora s.f.)

La población deste gran señor llamado Machiparo, que al parecer de todos duró más de ochenta leguas, que era toda una lengua, estas todas pobladas, que no había de poblado a poblado un tiro de ballesta, y el que más lejos no estaría media legua, y hubo pueblo que duró cinco leguas sin restañar casa de casa [...] salimos de la provincia y gran señorí de Machiparo. Yllegamos a otro no menor, que era el comienzo de Omagua (Carvajal 1942: 16-17).

Los omaguas antiguos, así como los cocamas de ahora, prefieren vivir en las islas o en las barrancas sobre los ríos grandes, como explica el franciscano Laureano de la Cruz y los jesuitas Cristóbal de Acuña y Samuel Fritz, y se distinguían de los indígenas que se orientan más hacia los bosques, los tapuyas.

En las dichas islas y con todas las incomodidades que hemos referido, pasamos tres años y nos conservó nuestro Señor con los miserables Omaguas en buena paz y amistad (De la Cruz 1999: 361).

Sesenta leguas más debajo de Tungurahua comienza la mejor y más dilatada provincia de cuantas en todo este gran río, encontramos, que es de los Agua, llamados comúnmente Omaguas [...]. Tiene esta provincia de longitud más de doscientas leguas, continuándose sus poblaciones tan a menudo, que apenas se pierde una de vista, cuando ya se descubre otra. Su anchura es, al parecer, poca, pues no pasa de la que tiene el río, en cuyas islas, que son muchas, y algunas muy grandes, tienen su habitación [...] (Acuña: 1986: 72).

Las sementeras o chagras de yuca y plátano con que se sustentan y casas y ranchos en que viven están de ordinario situadas en islas, playas o riberas del río, tierras todas bajas y anegadizas; $y$ aunque la experiencia les enseña de continuo que en tiempo de la creciente grande del río, quedan sin chagra y no pocas veces sin casa en que vivir, no por eso se saben resolver a vivir y hacer sus sementeras dentro del bosque y en tierra alta y apartada del río, diciendo, que la habitación de sus antepasados ha sido siempre el río Grande, y el bosque ser habitación propia de Aucas y Tapuyas [...] su vivir es andar de continuo por ríos y lagunas, pescando y remando, en lo cual son diestros más que ninguna nación (Fritz 1988: 306-307).

\section{3) Subsistencia}

La alimentación de los omaguas se basaba en el maíz, la yuca, la batata (camote), pescado, pejebuey (vaca marina) y las tortugas acuáticas y sus huevos. La técnica de almacenar la yuca podrida debajo tierra observada por los cronistas 
antiguos, se practica hasta hoy entre los omaguas, los cocamas (Regan 1983, I: 136137) y los ticunas (Peña 2003).

Sus alimentos principales eran maíz, yuca dulce y batatas y tenía masa de yuca rallada guardada en «hoyos debajo de la tierra a podrir, y de ello hacen pan y cierto brebaje» (Vázquez 1988: 37).

Cogen la yuca, que son unas raíces, de que hacen el cazabe, pan ordinario en todas aquellas costas del Brasil, y cavando en la tierra unas cuevas, o silos hondos, las sepultan en ellas, dejándolos muy bien tapados todo el tiempo que duran las crecientes, las cuales pasadas las sacan y benefician para su sustento, sin que por eso pierdan un punto de su valor (Acuña 1986: 50).

Susténtanse los Omaguas de los mantenimientos ordinarios de la tierra [...] El pescado de estos ríos es mucho y bueno, y hay muchas tortugas, que es muy buen sustento, y también el pejebuey, que es tan grande cada uno como un becerro y tiene la cabeza de la misma hechura, pacen yerba en las orillas de los ríos, es su carne como de vaca y de mucha substancia [...]. Comíamos de lo que ellos comían, y nos daban de buena gana, que nunca faltó, y bebíamos de los vinos que ellos hacían a más no poder, por no ser nada limpios (De la Cruz 1999: 360-361).

De la Cruz (ibid.:355) describió cómo sobrevivieron en un año en que perdían sus chacras por las inundaciones fuertes.

Iban en ellas (las canoas) los indios por el monte adentro a buscar frutas de palmas y de otros árboles, y pescado para comer, porque los mantenimientos que tenía sembrados casi todos se perdieron.

El padre Fritz también describió las formas de almacenar el maíz y la yuca.

Para que no les falten sus víveres por tiempo de la creciente grande, que empieza por marzo y dura hasta junio, y también después de ella hasta tener frutos de nuevas sementeras, hacen sus cosechas por enero y febrero y al maíz lo guardan colgado en sus casas, la yuca y mandioca la entierran en unos hoyos bien vestidos de hojas anchas; así la conservan debajo del agua y tierra, no sólo meses, sino uno y dos años más, de donde sacan, después que comienza a bajar el río, la que han menester para su gasto, dejando lo demás enterrado; y aunque esa yuca y mandioca se pudra, exprimida bien, es mejor y de más sustento que fresca, y de ella hacen sus bebidas, harina y cazaves (Fritz 1988: 307).

Asimismo almacenaban tortugas acuáticas en corrales.

Hacen para estos unos corrales grandes, cercados de palos, cavados por dentro, de suerte que, como lagunas de poco fondo, conserven siempre en sí el agua llovediza [...]. Cogen estas tortugas en tanta abundancia, que no hay corral de estos que no 
tenga de cien tortugas para arriba, con que jamás saben estos bárbaros qué cosa sean hambres, pues una sola basta para satisfacer una familia por mucha gente que tenga (Acuña 1986: 52-53).

\begin{tabular}{|c|c|}
\hline $\begin{array}{l}\text { LA CONSERVACIÓN Y ALn } \\
\text { [Este recuadro es un resumen del artíc } \\
\text { (2003) del Instituto de Investigaci }\end{array}$ & $\begin{array}{l}\text { ENAMIENTO DE LA YUCA } \\
\text { de la microbióloga Clara Peña Venegas } \\
\text { Científicas de Leticia, Colombia] }\end{array}$ \\
\hline $\begin{array}{l}\text { Los cronistas del viaje de Pedro de Ursúa en } 1560 \\
\text { describieron un método para el almacenaje de la } \\
\text { yuca. Es una tecnología autóctona de las tierras } \\
\text { inundables amazónicas, que está plenamente } \\
\text { vigente hoy entre los Cocamas y Ticunas. } \\
\text { Normalmente, la yuca se cosecha el mismo día de } \\
\text { su consumo o el día anterior. Con el paso del tiempo } \\
\text { la yuca, a diferencia de otros tubérculos, pierde } \\
\text { almidón y se vuelve leñosa, y no apta para el } \\
\text { consumo. Si se queda mucho tiempo debajo del } \\
\text { agua se pudre. } \\
\text { Cuando empieza a crecerse el río, para conservar } \\
\text { el almidón, cosechan y pelan todas las yucas: las } \\
\text { maduras, las no maduras y las que están perdiendo } \\
\text { su almidón. Las sumergen en agua para ablandarlas } \\
\text { durante dos a cinco días, dependiendo de la } \\
\text { temperatura del agua. Luego dejan la yuca fuera del } \\
\text { agua para eliminar algo del agua tapándolas con } \\
\text { hojas para evitar que los insectos pongan sus huevos } \\
\text { en la masa de yuca ablandada. } \\
\text { El comienzo del proceso de fermentación realizada } \\
\text { en el agua, que tiene una baja concentración de } \\
\text { oxígeno, fomenta el desarrollo de los }\end{array}$ & $\begin{array}{l}\text { microorganismos que degradan parcialmente el } \\
\text { almidón. Este proceso es una fermentación no } \\
\text { alcohólica que acidifica la yuca. Como la mayoría de } \\
\text { los microorganismos no pueden vivir en alimentos } \\
\text { ácidos, esta masa de yuca no se contamina } \\
\text { fácilmente y así puede conservarse más tiempo. La } \\
\text { masa de yuca parcialmente fermentada se pone en } \\
\text { costales y se entierra en huecos recubiertos de hojas } \\
\text { de bijao. } \\
\text { El proceso de maduración de la yuca es } \\
\text { bioquímicamente un proceso de fermentación } \\
\text { denominada heteroláctica, la cual se caracteriza por } \\
\text { producir oxidaciones incompletas de los azúcares } \\
\text { liberados. La yuca enterrada tiene una temperatura } \\
\text { más baja que la del medio externo, y queda aislada } \\
\text { sin oxígeno por el recubrimiento de hojas y la arcilla } \\
\text { del suelo. De esta manera la yuca puede durar } \\
\text { enterrada varios meses. } \\
\text { Cuando baja el nivel del agua, sacan la masa de yuca, } \\
\text { la prensan para eliminar algo del agua, la ciernen y } \\
\text { la tuestan para formar la fariña, que se come solo o } \\
\text { en una bebida, mezclada con agua y azúcar. }\end{array}$ \\
\hline
\end{tabular}

\section{4) Armas}

Entre las diversas armas que usaban los omaguas era la estólica, una tiradera propulsor de dardos o flechas, conocido también en la costa peruana en la cultura mochica (Ravines 1990: 29-34) y Paracas (Engel 1966: 182, 184, 185). La estólica aumenta la distancia de la propulsión de la flecha.

Sus armas son varas con puntas de palmas, tamaño de dardos de Vizcaya, tiradas con un aviento de palo o tiraderas de estólica (Vázquez 1988: 37).

[...] son estas estólicas unos palos tabledos, de una vara de largo, y tres dedos de ancho, en cuyo remate, a la parte de arriba, fijan un diente de hueso, en que hace presa una flecha de nueve palmos, con la punta también de hueso, o de palo muy fuerte, que labrado en forma de arpón, queda como garrocha, pendiente de aquel a quien hiere; 
ésta cogen con la mano derecha en que tienen la estólica por la parte inferior, y fijándola en el diente superior, la disparan con tan gran fuerza y acierto, que a cincuenta pasos no yerran tiro (Acuña 1986: 60).

Sus armas son regularmente la flecha y la estólica [...]. Hoy también usan a veces de la lanza, dardo y bodoquera, que son armas propias de indios de tierra firme, o como ellos dicen, «Tapuyas» (Fritz 1988: 306).

\section{5) Vestimenta y Cerámica}

Los hombres se vestían de una camiseta tejida de algodón pintada a pincel, y las mujeres una pampanilla y una mantilla del mismo material.

Isla de García [...] indios vestidos de camisetas de pincel labradas, las casas cuadradas y grandes (Vázquez 1988: 37).

La ropa que visten los Omaguas son, los varones unas camisetas de algodón pintadas que les llegan a la rodilla, sin mangas [...] los mayores se envuelvan en mantillas de algodón tan cortas y angostas, que los honestan muy poco (De la Cruz 1999: 360).

Andan todos con decencia vestidos, así hombres como mujeres, las cuales del mucho algodón que cultivan tejen no sólo la ropa que han de usar, sino otra mucha que les sirve de trato para las naciones vecinas, que con razón codician el trabajo de tan sutiles tejedoras; hacen paños muy vistosos, no sólo tejidos de diversos colores, sino pintados con estos mismos tan sutilmente, que apenas se distingue lo uno de lo otro (Acuña 1986: 72-73).

Usan hoy los hombres de calzones y camiseta de algodón tejida de pintada en bastante curiosidad; las mujeres se contentan con dos pedazos del mismo género, de los cuales el uno les sirve de pampanilla; con el otro cubren malamente los pechos [...] (Fritz 1988: 306).

Los omaguas también fueron conocidos por su cerámica fina policroma, sobre todo las urnas funerarias.

[...] Había mucha loza de diversas hechuras, así de tinajas como de cántaros muy grandes y candeleros de loza de la mejor que se ha visto en el mundo, porque la de Málaga no se iguala con ella, porque es toda vidriada y esmaltada de todos colores y tan vivas que espantan, y demás de esto los dibujos i pinturas que en ellas hacen son tan compasados que naturalmente labran y dibujan todo como lo romano [...] (Carvajal 1942: 30).

\section{6) Deformación del Cráneo:}

Los omaguas tenían la costumbre de apretar las cabezas de los bebes para que su cabeza creciera hacia arriba y no en redondo. Distinguía a los habitantes de 
la ribera inundable de los de la tierra firme. Esta práctica se ha encontrado en varios grupos del Caribe, los quijos, en la cultura nasca del Perú y en Argentina.

Son todos de cabeza chata, que causa fealdad en los varones, si bien las mujeres mejor lo encubren con el mucho cabello; y está en ellos tan entablado el uso de tener cabezas aplastadas, que desde que nacen las criaturas, se las meten en prensa, cogiéndoles por la frente con una tabla pequeña, que sirviendo de cuna, recibe todo el cuerpo del recién nacido, el cual puesto de espaldas sobre ésta y apretado fuertemente con la otra, queda con el cerebro y la frente tan llanos como la palma de la mano, y como estas apreturas no dan lugar a que la cabeza crezca más que por los lados, viene a desproporcionarse. De manera que más parece mitra de obispo mal formada que cabeza de persona (Acuña 1986: 73).

El modo que tienen en aplastarse las cabezas es el siguiente. Toman la criatura de pocos días nacida y cíñenle la cabeza por la parte de el cerebro con una faja de algodón ancha, y por la frente con una planchuela que hacen de cañas bravas que les coge desde los ojos hasta el cabello muy bien apretada, y de esta manera lo que la cabeza habia de crecer en redondo, crece para arriba, y queda larga, chata y muy desproporcionada (De la Cruz 1999: 360.)

Los portugueses llaman vulgarmente a los Omaguas con el nombre de Cambebas o Canga-Pevas, que quiere decir "cabezas chatas", porque el distintivo propio de esta nación es el llevar aplastadas la frente y llana como la palma de la mano; y en esto hasta el día de hoy ponen toda la gala, en especial las mujeres, hasta hacer mofa $e$ insultar a las de otras naciones con decir que tienen cabeza redonda a modo de «piache» o calabaza, como la gente salvaje del monte (Fritz 1988: 304).

\section{7) Organización Política}

Lo que llamó la atención de los europeos fue el orden y la obediencia de los omaguas a sus caciques, a diferencia de los pobladores del interior del bosque. Más debajo de la Isla de García encontraron muy poblada la tierra firme del margen derecho y en otras islas. Conocieron a un pueblo que se llamaba Carari (Vázquez 1988: 38) y llegaron a otro que se llama Manicuri, gente de la misma ropa y lengua y las mismas armas y casas. Tenía joyas de oro fino. Los dos pueblos parecían confederados (ibid.: 39), con una población de siete a ocho mil sobre las barrancas del río. Los españoles no podían averiguar qué había tierra adentro (ibid.: 39).

Es gente la de más razón y mejor gobierno que hay en todo el río [...] Son sujetos y obedientes a sus principales caciques, que no es menester más de una palabra para ver luego ejecutado lo que ordenan (Acuña 1986: 72-73). 
[Los omaguas] son gente apacible y la de más razón y gobierno de todo nuestro gran río, que tenían caciques principales a quienes estaban muy obedientes, que tenían comercio y comunicación con las naciones vecinas y otras cosas que nos obligaron a hacer de esta nación y provincia un muy grande concepto (De la Cruz 1999: 345).

[...] los Omaguas se precian de haber tenido siempre, aun antes de ser cristianos, una especie de policía y gobierno, viviendo muchos de ellos vida sociable, mostrando sujeción y obediencia a sus principales curacas (Fritz 1988: 306).

Otra indicación de que el pueblo omagua era una sociedad compleja es la especialización. Las tejedoras omaguas producían para la comercialización.

[...] del mucho algodón que cultivan tejen no sólo la ropa que han de usar, sino otra mucha que les sirve de trato para las naciones vecinas, que con razón codician el trabajo de tan sutiles tejedoras (Acuña 1986: 72-73).

Los omaguas estaban organizados para defender su territorio contra sus vecinos y contra los enemigos tierra adentro.

Tiene por la una y la otra parte del río continuas guerras con las provincias extrañas, que por la del Sur, entre otros, son los Curinas, tantos en número, que no sólo se defienden por la parte del río, de la infinita multitud de los Aguas, sino que juntamente sustentan las armas contra las demás naciones, que por la parte de tierra les dan continuada batería (ibid.).

Por la banda del Norte, tienen estos Aguas por contrarios a los Teamas, que según buenas informaciones, no son menos, ni de menos bríos que los Curinas, pues también sustentan guerras a los enemigos que tienen por tierra adentro (ibid. 1986: 73).

Tomaban cautivos en sus batallas y los trataban como miembros de la familia. Acuña señala específicamente que no los comían como aparentemente hacían otros grupos, pero sí mataban a los más valientes que percibían que podrían causarles problemas.

De los esclavos que estos Aguas cautivan en sus batallas, se sirven para todo que han menester, cobrándoles tanto amor que comen con ellos en el mismo plato (ibid.).

Otro índice de la complejidad de la sociedad omagua es la jerarquía o categoría de nobles. El P. Chantre y Herrera (1901: 83-84) describe el rito de iniciación para niños y niñas nobles, llamado Uscuimata (hacer publicar). Los niños que se presentaban se vestían de una cushma nueva y las niñas una pampanilla y manta nueva con una corona de plumas. Los llevaban en andas precedidos de danzantes con cascabeles al son de un tamborcito o pífano. Detrás salían cuatro mujeres de mantas largas muy pintadas y otra mujer daba golpes con una maza de caucho sobre un remo sujeto en una tinaja colgada como tambor. El zana (principal) les cortaba la punta del cabello, y los padrinos o madrinas les cortaban el sobrepeine todo el pelo. 
[...] son presentados otra vez los niños al zana, que levantándose de su asiento y llevándolos por delante, los va mostrando a los indios, diciendo a cada uno estas palabras: «Aiquiana ene zana» que quiere decir: «Este es tu señor».

Terminaba la ceremonia con un banquete.

\section{El Ocaso}

El ocaso del cacicazgo omagua se debe a la toma de esclavos por parte de los portugueses. También fueron fuertemente afectados por las epidemias. Los que probablemente eran hasta cien mil omaguas se quedaron reducidos a pocos miles de personas. Muchos de los que quedaron buscaron refugio en las misiones jesuitas, donde había un régimen de convivencia multicultural.

Después de integrarse en las misiones, los omaguas mantenían aspectos de su organización social y el liderazgo de sus caciques, pero no como un cacicazgo autónomo, sino bajo la tutela de los jesuitas. Sin embargo los omaguas, como otros grupos, se retiraban de las misiones o rebelaban cuando sentían presiones contra sus tradiciones, así como la sublevación que lideró el cacique Payoreva en 1699 y 1702 (Fritz 1988: 349-350).

Algo de la cultura omagua queda en el Perú en San Joaquín de Omaguas y caseríos aledaños, cerca de la desembocadura del Ucayali en el Marañón (véase Regan 1983; Chibnik 1994), otros se han fusionado con los cocamas y los kichua hablantes del Napo. En Brasil los descendientes se llaman cambevas (Jorna 1991). Otros herederos de la cultura omagua también se asentaron en la parte baja de los barrios de Belén y Bagazán en Iquitos (Hurtado 2007), donde tienen sus casas, tiendas y escuelas en el área inundable. En la época de la subida del nivel del agua, la gente transita por las calles en canoas. El idioma no se usa para la comunicación sino queda en la memoria de algunos ancianos cuyos padres no hablaban el castellano o portugués.

\section{LOS COCAMAS}

La tradición Caimito en el Ucayali es el antecesor de la de los cocamas. Hay dos fechas de $\mathrm{C}_{14}: 1320 \pm 60$ d.C. y $1375 \pm 105$ d.C. Es del estilo de negro y rojo sobre blanco (Lathrap 1970: 159) de la subtradición miracanguera de la tradición policroma.

El arqueólogo Daniel Morales (2002) dirigió las excavaciones en el sitio El Zapotal, una restinga de la cocha Yarina, afluente del río Samiria que desemboca en el bajo Marañón, entre el Huallaga y el Ucayali. Se encontró evidencia de ocupación humana con el hallazgo de «fragmentos de cerámica, restos de carbón, ceniza y suelo orgánico de color negro en las 30 cuadrículas abiertas» (ibid.: 56). 
Actualmente los cocamas siembran maíz en los gramalotales ubicados en los barreales. Primero entierran los granos de maíz y luego queman la vegetación, que produce ceniza y carbón que sirve de abono (Alexander Aquituari Ahuanari, comunicación personal).

Además de su valor en sí, es importante este sitio porque no da al cauce principal del Marañón. Cuando los primeros españoles, como Salinas y Ursúa, pasaron por el tramo entre el Huallaga y el Ucayali, lo encontraron aparentemente deshabitado. Pero los lugares de tierras inundables en el interior podrían haber sido bien poblados. Morales llamó a este lugar «uno de los sitios arqueológicos más grandes de la Amazonía Peruana, tal vez compatible con las descripciones de fray Gaspar de Carvajal en 1542» (ibid.). El hallazgo de suelo orgánico de color negro amplía el conocimiento de la extensión de este material en la Amazonía, y podría haber sido usado como un abono también en las restingas altas y tierras no inundables (véase Woods y McCann 2001).

En 1558 Juan de Salinas Loyola, con un grupo de soldados españoles, bajó por el río Marañón y después de entrar en el río Ucayali llegó a una provincia llamada Benorina ${ }^{10}$, posiblemente de habla pano (véase Morales 2002 para la relación entre los cocamas y los panos en el sitio arqueológico de El Zapotal). Luego dice Salinas: «Más adelante di en otra provincia mayor que se dice Cocama».

Salieron de muy buena paz y siendo todo buen hospedaje y lo mismo todo lo que duró la dicha provincia y lengua, en la cual distancia hay muchos pueblos y lagunas, que será hasta sesenta leguas, en la cual distancia hay muchos pueblos y lagunas pobladas y naturales (Salinas 1965: 200-201).

La legua en el viaje de Salinas, como en el de Carvajal, fue dos kilómetros. La población original podría haber sido más de cien mil (véase Myers 1988). Sin embargo, bajó drásticamente con las enfermedades. Los soldados habían estado expuestos a enfermedades antes de salir al Marañón. Salinas (1965: 200) dice:

Me embarqué en canoas con poco número de soldados, que fueron solamente los mas recios y sanos, y los demás por estar dolientes muchos de ellos [...]».

Se determino embarcar en él (Marañón) en canoas con la gente de soldados que halló con más salud, porque le habían adolecido la más parte de los soldados [...] (ibid.: 213).

Después de la exploración del Ucayali, según Saabedra (1965: 245), los cocamas sirvieron a Juan de Salinas y lo llevaron río arriba al estrecho del Pongo.

10 En shipibo «beno» significa «errante». «Benórina» es un nombre propio y podría ser el nombre de una comunidad o de su cacique). López de Velasco (1971) no dice «Benorina» que es un nombre propio femenino, sino «Benorima» que es un nombre propio masculino. (Aquiles Vásquez Gordon, shipibo: comunicación personal). 


\section{1) Lengua}

Ana Suelly Cabral (1995) presentó evidencia del origen no genético de la lengua cocama con respecto a la familia lingüística tupí, pero confirmó el hecho de que el sistema fonético y el vocabulario son muy parecidos al tupinambá del siglo XVI. El idioma cocama tiene una afinidad con la familia tupí-guaraní, aunque no tuviera una relación genética con esta familia lingüística.

Existen algunas frases en cocama del siglo XVII. En 1681, setenta y cinco canoas llenas de cocamas entraron en la misión de la Laguna para rogarle al padre Lorenzo Lucero que los acompañara en un viaje para escaparse de la peste. Cuando el padre no aceptó, se despidieron con las siguientes palabras en cocama: Caquire tanu papa ${ }^{11}$, Caquere $^{12}$ ura Dios icatotanare ${ }^{13}$ : "Quédate con Dios, hombre esforzado; Dios te guarde y te dé mucha vida» (Lucero 1986: 322). Luego se fueron a vivir con los omaguas en una isla durante un año.

El P. Veigl (2006: 122) dijo que sólo había pequeñas diferencias dialectales entre el cocama y el omagua.

La lengua de los Cocama no se distingue de la de los Omagua, salvo insignificantes particularidades dialectales. Es la más agradable de todas que se hablan en esta área, si bien la fonética de los Cocama es algo dura. Los misioneros la aprendieron con más facilidad que otra.

En las misiones los cocamas estaban en relación estrecha con los panos y hablantes de otros idiomas, y usaban el quichua como lengua general hasta mediados del siglo veinte. Todo esto habría influido en el habla del cocama.

\section{2) Asentamiento, Adaptación a la Llanura de Inundación y Transporte}

Los antiguos cocamas así como los actuales (véase Rivas 2004) estaban íntimamente vinculados a los ríos principales y en 1558 vivían en pueblos grandes a lo largo de 120 kilómetros en el Ucayali.

[Los cocamas] Tienen las poblaciones sobre las barrancas de los ríos, muy bien formadas (Salinas 1965: 202).

Es gente muy lúcida y bien dispuesta y agestada; tienen sus poblaciones sobre barrancas del río juntas a manera de pueblos de doscientas y trescientas y cuatrocientas casas (ibid.: 207).

[Los cocamas] se dedican a la pesca más que a la caza, estando por tanto muy familiarizados con los ríos y lagunas, y habilísimos tanto en la construcción de sus

11 Al cacique de los Omagua en el siglo anterior le decían «pappa» (Vázquez 1988: 37).

12 «caquire»

13 Según el cocama Elías Mozombite debe ser «icatatanare» o «icuatatanuri». 
canoas como en utilizarlas para los fines más diversos; no menos hábiles son en ingeniarse para coger todo lo que vive en el agua (Veigl 2006: 122).

Actualmente los cocamas también prefieren vivir en las barrancas sobre los ríos, en las islas o en las restingas altas.

\section{3) Subsistencia}

Las crónicas hablan de la gran abundancia de alimentos que tenían los cocamas,

[...] comidas, de todo género en gran abundancia y frutas; pescados, muchos y muy buenos y diferentes; montería y caza; loza mejor y más prima y galana que hay en el mundo (Salinas 1965: 201).

Este río de Cocama [...] tiene mucho pescado de diferente clase y mucha tortuga, y en la playa hay mucha cantidad de huevos de ésta, y en la misma playa se toma mucha cantidad de pájaros ${ }^{14}$ del tamaño de palominos que son muy gordos y sabrosos (Vázquez 1988: 35)

Para preparar el viaje de Ursúa, el capitán Juan de Vargas y otros surcaron el Ucayali veintidós jornadas ${ }^{15}$ y llegaron a un poblado donde hallaron mucha comida, sobre todo maíz.

[...] de todo seproveyó bien y cumplidamente, así de maíz como de otras comidas, fruta y regalos de la tierra, lo cual hizo meter en las canoas, en las cuales metió indios de aquella provincia en colleros porque no se le huyesen, y en cada una dos españoles que los guardasen (Ortiguera 1968:232).

Había alimentos suficientes para mantener a los sesenta hombres de Vargas durante dos meses mientras esperaban a Ursúa, y a las más de ochocientas personas recién llegadas con Ursúa durante unos días más. Además del maíz probablemente se alimentaban de pescado y tortugas.

\section{4) Armas}

El arma principal de los cocamas fue la estólica, a diferencia de los panos que usaban el arco y flecha.

Manejan con gran pericia sus lanzas que si bien, no las disparen igual que todos los pueblos del Ucayali mediante el arco, sino, como es uso general en el Marañón, sirviéndose de un dispositivo en forma de una angosta tablita, llamada "estólica», alcanzando de este modo la misma distancia y certeza de una flecha; se trata de un

\footnotetext{
14 tibi: gaviota del río, ave acuática comestible que pone sus huevos en la playa.
}

15 Más o menos por lo que ahora es el distrito de Puinahua, provincia de Requena. 
invento original y muy ingenioso, mediante el cual, sujetando sólo con la mano derecha levantada la lanza de bien nueve palmas de largo, saben imprimirle simultáneamente un impulso tan cierto que rara vez yerra el blanco a una distancia de cincuenta pasos (Veigl 2006: 122).

\section{5) Vestimenta y Cerámica}

Los cocamas usaban ropa tejida de algodón pintada a pincel. Actualmente no se visten así, pero los shipibo-conibo y los yine yamis (piros) continúan esta tradición.

[...] la gente es de mucha policía así en los vestidos, porque son de algodón y muy primos con pinturas muy diferentes y galanas; usan plumería y plumajes y joyas de oro y plata de que adornan sus personas (Salinas 1965: 202).

[...] gente de mucha razón y policía, de ropa de algodón muy pintada así de pincel como labrada; joyas de oro y plata, de que adornan sus personas, de patenas en los pechos y en las muñecas de los brazos, y chaquira de oro y plata colgada de las narices y orejas y cedacillos de plata en las cabezas a manera de aros de cedazos; gran plumajería (ibid.: 207).

La cerámica cocama, así la de los omaguas y mainas, era policroma, con pintura roja, blanca y negra (véase Morales 2008:215 eneste número). Métraux (1963:695) dijo que las fareras cocamas eran las mejores de América del Sur.

\section{6) Deformación del Cráneo}

Los cocamas deformaban el cráneo del niño, pero en el siglo XVIII ya habían dejado esta práctica.

[Los cocamas] Han dejado la costumbre bárbara, que tenían en común con los Omagua, de deformar la cabeza de los niños, apretando la parte superior del cráneo entre dos tablitas, hasta tal punto que es raro encontrar al presente a un Cocama con la cabeza deformada (Veigl 2006: 122).

\section{7) Organización Social y Política}

Los españoles destacaban la situación de los pueblos de la llanura de inundación que se distinguían de los grupos de tierra adentro en cuanto a una organización con caciques muy respetados y más allá de los jefes de familia.

Los caciques que hay en cada pueblo son muy respetados de los naturales (Salinas 1965: 201).

Los caciques se distinguían por el ornamento de su cuerpo.

Son obedecidos y respetados los caciques mucho más que los de atrás, y así en esto como en el ornamento de sus personas, representan ser señores (ibid. 207). 
En el siglo XVII los cocamas reconocieron al soldado Pedro de la Torre, hijo de una mujer xibitaona, como si fuera un cacique suyo.

[...] oyendo que les hablaba en su lengua, decían los Cocamas que era el alma de un cacique que poco antes había muerto: y así le reconocían, dándole de sus regalos. Un cacique del pueblo le sacó unos niños, hijos del muerto, y le dijo: estos son tus hijos, y de esta casa para arriba son los indios tus sujetos; los demás, para abajo, son míos (Figueroa 1986: 207).

Hablar de dos caciques, el de arriba y el de abajo, indicaría una forma de organización política dual. La idea de la reencarnación expresada en este relato es un aspecto de su cosmovisión vigente hoy en día entre los cocamas (Regan 1983, I: 214).

Una de las razones de su buena organización fue la defensa de su territorio, sobre todo contra los chipeos, aunque más tarde entrarían en alianza con ellos en contra de los españoles.

Tienen guerra, o por mejor decir, la hacen ellos a varias naciones de su río Ucayali y del Marañón, y ellos la suelen padecer con mucho daño suyo, de los chipeos, que están arriba de sus tierras, si bien tal vez les dan el retorno (Figueroa 1986: 211).

\section{El Ocaso}

El pueblo cocama, después de los contactos con los españoles, se quedaron diezmados por las epidemias, y sus vecinos tierra adentro, los chipeos, pudieron lograr el dominio en el río Ucayali. En una rebelión de los cocamas contra los españoles instigada por los chipeos, murió asesinado el padre Francisco de Figueroa en 1666. El padre Veigl (2006: 121) habla del mal ejemplo de chipeos en este caso.

Varios autores han culpado del crimen a don Clemente Pacaya, el cacique cocama, o a un hombre criado por los jesuitas. Son versiones de personas que no fueron testigos de los hechos. A diferencia de estos relatos, la versión del historiador jesuita de la época, Pedro de Mercado (1957: 321), da detalles precisos, basados en cartas fidedignas llegadas al colegio de los jesuitas en Quito. Dice que los asesinos del padre eran los mismos xitipos que habían matado a los franciscanos unos años antes, como reportó el mismo padre Figueroa (1986: 205), que los llama chipeos.

Hacia las cabeceras (del Ucayali) tienen misión los Padres de San Francisco (...) donde mataron (dicen que los Chipeos), cuatro religiosos de esta sagrada religión y tres soldados, estando dormidos.

El relato del P. Mercado (1957: 320), en su estilo panegírico, narra la muerte del padre Figueroa.

[...] Entonces le hirieron segunda vez en la cabeza con la macana, y el padre volvió con mucha serenidad a levantar los ojos al cielo pidiendo misericordia, y luego 
volviéndose a los indios dijo con voz tierna: ¿Por qué hijos míos cocamas quitáis la vida a vuestro padre? Respondióle el cacique Xitipo: no os matan no los Cocamas sino los Xitipos, y esgrimiendo la macana le quebró la pierna derecha, y sin embargo, de esto prosiguió ayudando a sus compañeros [Xeberos] moribundos, y sin tenerle lástima los bárbaros descargaron las macanas a porfía sobre su venerable cabeza y corona para gozase la de mártir en el cielo [...]. Si el P. Figueroa pensaba que los xitipos eran cocamas, los xitipos habría tenido cabezas chatas y habrían vestido ropa pintada.

Llegó tarde don Clemente Pacaya que había dicho que «su intento era vengarse de los españoles, xeberos y guallagas, no hiciesen mal ninguno a los padres si los encontrasen» (ibid. 319). El historiador habla de la tardanza del don Clemente.

Llegó a este tiempo el gobernador don Clemente que no pudo antes por habérsele aplomado de suerte la canoa que no la podían mover sus remeros por más que le metían canaletes, pero al fin, vencida la dificultad llegó y viendo el cuerpo tronco, no se pudo contener llorando a gritos, y a su ejemplo muchos de los Cocamas; pero los alevosos retuvieron a Pacaya de manera que le obligaron a prorrumpir en estas palabras, «pues habéis cometido tan estupenda maldad y supuesto que hemos perdido la gracia de los padres y no tenemos ya quien nos defienda de los españoles [...] (ibid.: 120).

Los españoles vencieron a los rebeldes, ejecutaron a las cabecillas y enviaron a los demás participantes a las encomiendas en Borja y Moyobamba. Los restantes se agruparon con otras etnias en la misión de los jesuitas de Santiago de la Laguna en 1670. Este hecho marca el ocaso del cacicazgo de los cocamas. Durante su presencia en las misiones de vez en cuando brotaba resistencias, muchas veces por las exigencias de los jesuitas o para escaparse de las epidemias. Dentro de las misiones los caciques mantenían su autoridad, pero sin la autonomía anterior.

Actualmente en el siglo XXI están agrupándose en organizaciones y federaciones modernas en Perú, Colombia y Brasil. Muchos cocamas optaron por no transmitir el idioma a sus hijos porque el castellano era más útil. A pesar de este hecho, hay un pequeño movimiento que intenta recuperar el idioma.

\section{LOS MAINAS Y CIPITACONAS}

Otros pueblos que han ocupado un lugar central en los primeros contactos con los españoles son los mainas y cipitaconas. Vivían río arriba de los cocamas en el margen izquierdo del río Marañón, entre el Pongo de Manseriche y el río Pastaza, donde los encontró Salinas de Loyola en 1558.

Pasada la dicha angostura, se dio en una población de gente diferente de lengua y traje de la que atrás dejaba (en el río Santiago), los cuales me avivaron la misma noticia, figurándomela en mayor grado de riqueza, que me obligó a proseguir mi camino adelante por verla y palparla; $y$ andadas veinte y cinco leguas de la dicha población, llegué a una provincia que se dice Maynas, gente muy lúcida y de gran disposición en 
comparación de la ordinaria de Indias. Era diferente lengua de los de atrás, gente muy guerrera y belicosa y que por tales eran tenidos por los comarcanos; [...] Reparé poco en esta provincia, por entenderse mal la lengua, que era muy escura y por perseguir mi noticia. (Salinas 1965: 200-201).

Algunos autores piensan que los mainas eran los antepasados de los que actualmente habitan esta zona, los candoshi o jíbaros (Tessman 1999: 158; Taylor 1988: 104). No se descarta la posibilidad de una presencia de los antepasados de los candoshis o jíbaros, pero no en la zona inundable sino en el interior.

En el siglo XVI los españoles habían establecido encomiendas más arriba del Pongo de Manseriche en los ríos Santiago y Nieva. Los indígenas de Santiago de las Montañas rebelaron contra los españoles en 1569 por malos tratos y excesivo trabajo en las minas.

Que el capitán Juan Sevillano de la Cueva [...] en 1569 acompañó al general Juan de Salinas, gobernador de Santiago de las Montañas a apaciguar y sujetar los naturales de aquella tierra, que se habían alzado en los Jíbaros [...] (Martín Cuesta, 1984, II: 432).

En 1585-86 una epidemia en la cuenca del Alto Amazonas llegó a los pueblos españoles de Loyola y Santiago de las Montañas y la encomienda de Cangasa.

La serie de epidemias de 1585-1591 también invadió la cuenca del alto Amazonas y podría haber bajado río abajo. Hemos indicado el impacto en Jaén, donde la población nativa bajó de 30,000 a 1,000. Yaguarsongo y Pacamores fueron duramente golpeados. Entre 1585-86 se reportaron «pestilencia y enfermedades» en Loyola y Santiago de las Montañas. En Cangasa se redujo en más de una tercera parte (Cook 1998: 131).

Los españoles extraían a los mainas y cipitaconas para llevarlos a sus encomiendas por Nieva y Santiago, donde existía una situación de trabajo forzado, para reemplazar a los indígenas que morían por las rebeliones y por enfermedades contagiosas. En 1580 ya había un grupo encomendado en el río Santiago llamado civitaonas (Taylor y Landázuri 1994: 183).

En las expediciones de los mainas, varias veces atacaron y destruyeron los pueblos españoles para que no llevaran a más gente, y posiblemente se habrían llevado las herramientas de los españoles. Este hecho podría explicar los ataques posteriores de los cocamas contra los mainas supuestamente para obtener estos objetos de metal tan cotizados.

La adquisición de herramientas era un motivo para los ataques a otros pueblos. Más tarde, después de la formación de la misión jesuita entre los cocamillas, los cocamas en la época del creciente de los ríos, pasaban del Ucayali al Huallaga para llevarse las herramientas de metal, además de cortar sus cabezas para realizar sus danzas rituales. 
[...] salían todos los años en armadas de cuarenta y cincuenta canoas, por una travesía en que en dos partes las varaban algún trecho [...] tomaban puerto en el río Guallaga, y corriendo por él y por el Marañón quebradas y lagunas, degollaban a los que encontraban, llevándose las cabezas, que era el fin (fuera del pillaje de herramientas) de sus jornadas (Figueroa 1986: 205).

En 1661, Figueroa (1986: 308) habla de la importancia de la fragua.

Importa mucho fomentar y conservar la fragua que está en Xeberos y otra que se va disponiendo en los Coronados [...]. La causa es que su vida y sustento depende de sus herramientas que se hacen en la fragua; hachas y cuchillos con que limpian y desmontan estos arcabucos en que hacen sus sementeras y comidas y fabrican sus casas; los anzuelos y puyas con que pescan y otros instrumentos de yerro. [...]. En las ocasiones que se han alborotado para amotinarse, el principal reparo que les retarda es el haber de perder el beneficio de las herramientas; $y$ cuando han resuelto a algún alzamiento, como fue el de los Maynas y otro de Cocamas, solamente salvaban las vidas de los herreros con las fraguas.

El jesuita Jean Magnin (1998: 180) describe con mayor detalle el valor de las herramientas.

Para ganarles no se sirven de razones o argumentos, que de eso no entienden, sino de dádivas y agasajos, hachas, cuchillos, agujas, herramientas, son las más convenientes razones; que como en sus rincones no tienen nada de eso sirviéndose solo de hachas de piedra, colmillos de animales, huesos y del fuego, para cortar palos y labrar sus canoas, reconociendo en la herramienta tan grande ventaja, se mueren por recibir alguna dádiva de esas, dando aun sus propios hijos por un hacha, que eso vale una china, si su padre no quisiere venir al pueblo, y siendo los hurtos entre ellos casi incógnitos, por las herramientas se hacen varios, robando y matando a sus vecinos para quitárselas, que en eso solo tienen puesta su codicia.

Para pacificar a los mainas, en 1619, los españoles entraron en su territorio donde fundaron la ciudad de San Francisco de Borja creando encomiendas entre esta etnia. Por otra parte, los mainas habrían buscado el amparo de los españoles contra el acoso de los cocamas (Taylor y Landázuri 1994: 356).

Los españoles justificaron su entrada a los mainas para hacerlos cristianos y vasallos de «su majestad católica, el rey de las Españas». Repartieron a los indígenas en 24 encomiendas, y trataron a los mainas como esclavos. El Padre Chantre y Herrera (1901: 47-48), que tuvo acceso a documentos de la época y la tradición oral de los jesuitas, a fines del siglo XVIII, describe la situación de los mainas.

Toda carga del sustento de la ciudad cayó sobre estos miserables (los indios) que, hechos antes a vivir a sus anchuras y libertad, sin que los apremiase ninguno, llevaban muy mal aquella dura sujeción de emplear dias enteros en buscar caza y pesca para 
las familias. Allegábase a esto el trato duro y áspero de los encomenderos, que los trataban como esclavos, sin que fuese parte para mitigar tanto rigor y ponerlo en razón toda la vigilancia y autoridad del gobernador mismo.

\section{1) Lengua}

Según el documento de Saavedra, los mainas hablaban la lengua de Brasil, que se supone era el tupí o una lengua muy similar.

Hablan su lengua materna, que no es quichua, ni aymará, y comunicándola con un Padre de la Compañía de Jesús que ha estado en Brasil, dice que es la misma que hablan los indios de allá (Saavedra 1965: 245).

El Padre de la Compañía de Jesús a quien alude fue el padre Juan Manuel Anaya, que había participado en el viaje de Pedro de Ursúa. El padre Pablo José de Arriaga, en una carta al Padre General de los Jesuitas, padre Claudio Aquaviva, dice:

Un Padre de los Nuestros, antes de ser de la Compañía, navegó por él (Amazonas), embarcándose en un bergantín que hicieron más arriba de los Chachapoyas, como doscientas leguas de Lima, más de cuatrocientas leguas, hasta desembocar al Mar del Norte.

El padre José de Acosta escribiendo en 1590, en su obra Historia Natural y Moral de las Indias (1962: 71-72) dice lo siguiente.

Mas hablándose de ríos con razón pone silencio a todos los demás aquel gran río que unos llaman de las Amazonas, otros Marañón, otros el río de Orellana [...]. La anchura y grandeza tan maravillosa de este río, que justamente se puede llamar Emperador del los ríos, supímosla de buen original, que fue un hermano de nuestra Compañia, que siendo mozo le anduvo y navegó todo, hallándose a todos los sucesos de aquella extraña entrada que hizo Pedro de Orsúa, y a los motines y hechos tan peligrosos del perverso Diego de Aguirre, de todos los cuales trabajos y peligros le libró el Señor para hacerle de nuestra Compañía.

El testimonio del P. Juan Font (Jiménez de la Espada 1965: 260) a Felipe III en 1601 relata que el padre Anaya había hablado con él.

A esta tierra entró un capitán [Pedro de Ursúa] con 500 hombres en tiempo del Marqués de Cañete. Estos contaron grandes cosas de la tierra y de la infinitud de gente que hallaron, y yo traté mucho con un Padre de la Compañia de Jesús, llamado Anaya, que entró con ellos antes de ser religioso, y me contó grandes cosas.

Salinas, después de haber estado en territorio jíbaro, necesitaba tres intérpretes para entenderse con los cipitaconas ${ }^{16} \mathrm{y}$ mainas.

$\overline{16}$ López de Velasco (1971: 231) dice «Zipitacones». 
[...] pasé y descubrí la provincia de Cipitaconas y otra que se dice Maynas; gente de gran disposición y fuerza y de mucha policía y de plumería y la ropa muy pintada de pincel, la lengua muy diferente de las de atrás, así la de Cipitaconas como de la de los Maynas; y así, para entenderme con ellos, fue por tres intérpretes, que fue no poca ventura hallarlos [...]. Toda esta gente dicha y provincias es de más policía que la de atrás y belicosa (Salinas 1965: 206).

Salinas dio a entender que la lengua de los mainas era la misma que la de los cipitaconas.

(... ) la lengua muy diferente de las de atrás. Así la de los Cipitaconas como la de los Maynas; (...) asimismo otras provincias y poblaciones casi de la misma lengua de estos dos que he dicho, porque se entendian, y la provincia de los Marcayos (Salinas 1965: 206).

No dice «las mismas lenguas de estos dos», sino «la misma lengua de estos dos», indicando que hablaba el mismo idioma. Si Salinas (1965: 206) necesitaba tres traductores para los mainas y cipitaconas, después de haber estado con jíbaros, entonces la lengua maina y cipitacona no sería jíbara.

Saavedra (1965: 243) dice que en 1619 cuando pasaron por el Pongo de Manseriche encontraron a los mainas a tres leguas abajo y no menciona a los cipitaconas que había encontrado Salinas en 1558. Un documento publicado por Taylor y Landázuri (1994: 183) indica un grupo llamado «Civitaonas» en una encomienda del río Santiago en 1580. Por otra parte, Figueroa presenta el caso del soldado, hijo de una mujer xibitaona, que en 1644 encontró que los cocamas hablaban el idioma que había aprendido de su madre (Figueroa 1986: 206, 253).

Dada la similitud fonética de «cipitacona», «zipitacones», «civitaona» y «xibitaona», se podría suponer que se trata de la misma población. Entonces, este grupo habría sido extraído de su lugar de origen debajo del Pongo de Manseriche y colocado en una encomienda del Río Santiago. Así se aclararía la situación de los tupíes de la región. Los mainas hablaban la lengua de Brasil, los cipitaconas hablaban la misma lengua que los mainas, y los xibitaonas hablaban la misma lengua que los cocamas. Y sabemos que la lengua cocama era muy similar a la de los omaguas y el tupinambá (véase Figueroa 1986: 253).

Otro indicio de la relación entre estas lenguas se encuentra en la visita de Salinas a los cocamas en el Ucayali. Dice que se entendía con ellos por medio de intérpretes. Podrían haber sido algún maina o cipitacona.

[...] la lengua es diferente pero con intérpretes me entendía con ellos (Salinas 1965: 202).

Es lengua diferente de las de atrás, que por gran ventura, y por vía de intérpretes me entendí con ellos (ibid.: 206). 
Serían los mismos guías que acompañaron a Salinas y que conocían la ruta, como señala en un memorial de 1571.

[...] dio en una boca de un río poderoso que venía de mano derecha, al cual llegó el día de Sant Miguel, el cual nombre le puso; y las guías que llevaba le dijeron que había de subir por aquel río arriba para dar en la tierra de que le habían dado noticia y en grandes provincias y poblaciones (ibid. : 213).

\section{2) Adaptación a la Ribera Fluvial, Asentamiento y Transporte}

Una característica que destaca a los mainas era el afán de viajar por los ríos y Saavedra notó que peleaban mejor desde la canoa que en tierra.

Toda esta gente dicha y provincias es de más policía que la de atrás y belicosa. Es gran gente del agua; tienen muchas y muy buenas canoas en que navegan (Salinas 1965: 206).

En lo que se ocupan es en cazar en el monte, y en pescar, y hacer sus canoas, y a andar por el río en ellas de una parte a otra [...] y es gente que pelea mejor en el agua que en tierra, por ser muy ciertos en las flechas, que las tiran desde la canoa, travéndola tan ligera como si fuera un caballo arrendado (Saavedra 1965: 245).

\section{3) Subsistencia}

Cultivaban maíz, yuca, camote, frijoles, maní, zapallos entre otros productos, pero su fuente de proteína provenía de los ríos y lagunas.

De lo más usan es pescado, que tienen en abundancia todos los ríos que entran en el Marañón, y el mismo y muchos brazos que hace, los cuales son de muchos géneros, como es el tiburón, la doncella, la capitana, el sábalo y dorado, todos muy grandes. Hay también boquichicos y otros géneros de pescado menudo, que con facilidad le cogen con anzuelos, y flexándole [flechándole] y embarbascándole con una raíz que llaman barbasco (ibid.: 247).

Hay muy grandes tortugas y coteas [hicoteas] en abundancia, de que también se aprovechan para comer, y de los huevos, que hay muchos en las playas del río (ibid.).

\section{4) Armas}

El mismo autor menciona el uso de la estólica como arma.

Las armas que usan son flechas que tiran con estólica, y lanzas de chonta de dos varas $y$ media a tres, $y$ de rodelas [...] (ibid.).

Dice también que temían guerra con la provincia de Aguano y Cocamas (ibid). 


\section{5) Vestimenta y Cerámica} de pincel.

Entre los mainas, las mujeres tejían, y el diseño en la ropa de algodón se pintaba

Vestían ropa de algodón muy pintada, y usaban mucha plumería de todos colores, la cual asentaban por gran artificio en sus rodelas y lanzas y en otros instrumentos de guerrero (Salinas 1965: 206).

[...] vístense de mantas de algodón que se da en la tierra y las hacen las indias y labran de pincel, de diferentes colores, con mucha curiosidad; el traje es camiseta larga hasta la pantorilla, y otras más cortas, sin calzones, y las indias andan con manta corta ceñida por la cintura, que no les cubre el pecho, y de largo hasta las pantorrillas y más abajo [...] (Saabedra 1965: 245).

Usaban las mantas cachibangos (petates) como moneda.

[...] lo que más estiman son las mantas y cachibongos, que les sirve de moneda.

De las cosas de acá fuera [...] son hacha, azuelas, machetes, cuchillos, puyas, firgas y anzuelos y todas las cosas de hierro para sus chacras y pesca, y las hachas y anzuelos para hacer canoas, de que usan mucho, por andar de continuo en el agua [...] (ibid.:246)

También hacían cerámica policroma.

Tienen mucha loza de barro que hacen pintada de colorado, negro y blanco (Ibid.).

\section{6) Deformación del Cráneo}

Tenían las cabezas chatas.

Es esta gente dócil y fiel, de buena estatura, corpulentos y fornidos, buenos rostros, y las cabezas por detrás chatas como asturianos, cabello largo hasta las corvas de las piernas poco menos (ibid.: 1965: 245).

\section{7) Organización Política}

El cronista Saavedra describe el origen y características de este cacicazgo: orden, respeto y sucesión hereditaria de los caciques.

[...] y en su gobierno son más ordenados que los indios de otras provincias arriba descritas, porque son más obedientes y respetan más a sus caciques.

No tienen reyes, sólo respetan y obedecen con mucha puntualidad a sus caciques, los cuales tienen por tradición que los primeros que usaron de cacicazgos y se introdujeron en ellos por más valientes y briosos y de allí ha venido la sucesión de los hijos. 
No dan a sus caciques tributos particulares más de tan solamente hacerles sus chácaras y casas en común, y cuando van a alguna parte, llevan los indios que quieren sujetos suyos, que les bogan en las canoas y les pescan y cazan en el monte; y esto hacen en obediencia y voluntad (ibid.: 246).

Taylor (Taylor 1988: 101) comenta que los mainas se parecen a los jíbaros ribereños con una excepción muy notable. Estaban organizados en un cacicazgo.

Si se exceptúa la presencia eventual entre los Mayna de un cacicato [sic] cristalizado y hereditario que no existía entre los Jivaro.

\section{El Ocaso}

El P. Figueroa habla de un cacique maina que fue capturado por los españoles y llevado a Nieva, y de un yerno suyo que ayudó a asentar a los mainas dispersados por la presencia española.

[...] un indio de Nieva, llamado D. Antón, el cual, con ocasión casado de los que estaban en paz, y estar casado con una Mayna, hija de un cacique mayna de los que habían cautivado los españoles y llevado a Nieva, tuvo mucha mano y cabida con los Maynas para sacarlos de sus ríos y quebradas a que se poblasen en el Marañón y esperasen a los españoles (Figueroa 1986: 160).

Fundóse [Borja] después de varias entradas que en tiempos antiguos hicieron los vecinos de Santiago y Nieva, en orden a sacar piezas y reprimir insolencias y daños que hacían los Maynas a esas ciudades (ibid.).

Con sola esta provincia de indios Maynas, el Gobernador y Capitán General D. Diego Baca fundó la ciudad de San Francisco de Borja [...] Y señalóle hasta veinte y cuatro encomenderos, haciendo y repartiendo otras tantas encomiendas para ellos, de todos los indios Maynas, que son los que han servido y sustentado con su servicio y tributos a la ciudad y sus vecinos (ibid.).

Después de la fundación de Borja, seguían tratando a los mainas como esclavos.

[...] sujetando indios, sobre quienes toman muchas licencias contra leyes divinas y humanas [...]. Hacianse algunas injusticias graves a los indios, nacidos de ignorancia o malicia como era servirse de ellos como de esclavos, echándoles cargas y servicios que no debian por sus tasas de tributos. (idid. 158).

A los mainas, que llamaban «piezas», los repartieron entre los soldados y vecinos.

Sacábase muchas gente de varias provincias, yendo en armada, cogiéndola y trayéndola en gruesas tropas que repartían entre los soldados y vecinos, que son las que llaman piezas, de que se ocasionaban en esas desdichadas gentes lastimosas mortandades, 
pues dentro de pocos días apenas quedaron vivos la décimas parte. Estas y otras insolencias había que los llevaba a su perdición (ibid.).

Los españoles fundaron el pueblo de San Francisco de Borja para controlar a los mainas, pero seguía el maltrato resultando en el levantamiento de los mainas. El padre Veigl (2006: 107-8) habla del diezmado pueblo de mainas. En el contextote esta situación, el gobernador había invitado a los jesuitas a establecer sus misiones. Algunos de los mainas se juntaron en las misiones jesuitas, y otros fugaron, pero ya el reconocido cacicazgo de los mainas ya no existía como tal.

A causa de este alzamiento y otros, seguidos de frecuentes epidemias, incluso debido a suicidios e infanticidios practicados por desesperación y aborrecimiento del dominio español, esta nación quedó en pocos años tan diezmada que en el pueblo perteneciente a San Borja apenas sobrevive una u otra familia.

El mismo autor dice, escribiendo poco después de 1768, que hacía poco encontraron unos «Mainas salvajes», pero la descripción de su vestido y armas y otros aspectos de su cultura es muy diferente de las descripciones de Salinas y Saavedra. El vestido de los hombres era como un costal que llegaba hasta los tobillos y las mujeres andaban desnudas salvo un angosto delantal. También a veces se vestían de una tela hecha de las hojas de la palmera achual. Sus armas eran la lanza y la cerbatana. Según Veigl «La lengua de los Mayna es sumamente dura y no tiene nada en común con otras» (ibid.). Podría haber sido gente como los urarinas. Si los descendientes de los mainas se habían retirado a lugares menos accesible del bosque, se habrían adaptado a este ecosistema. En cuanto a la lengua, se puede reemplazarla en dos generaciones, como está ocurriendo ahora en el cambio del idioma cocama al castellano.

\section{Comentario}

Cuando llegaron los europeos, existían varios cacicazgos amazónicos, no sólo en Brasil y Bolivia, sino en la región del Alto Amazonas en lo que ahora es el Perú. Los cronistas distinguieron entre las etnias acéfalas del interior y las sociedades con liderazgo permanente y hereditario cuyos asentamientos se encontraban en las barrancas sobre los ríos grandes, alrededor de las lagunas y en las islas. Cada una de las sociedades ribereñas presentadas aquí podría haber tenido más de cien mil personas. Ya en el siglo XVI, con los primeros contactos con los europeos, las epidemias estaban reduciendo la población drásticamente.

Tenían abundantes alimentos, basado sobre todo en el pescado, las tortugas y sus huevos, la yuca y el maíz y técnicas de almacenaje que permitía mantener a poblaciones grandes. Otras características eran la ropa tejida de algodón y pintada a pincel, cerámica policroma, las cabezas chatas y el uso de la estólica para tirar sus flechas. 
La concentración de recursos en la llanura de inundación dio una gran ventaja a las sociedades que la dominaron. Según Carneiro (1970) y Lathrap (1970) la competición para dominar y controlar estos recursos habría dado lugar a la guerra, la necesidad de caciques permanentes y la evolución de cacicazgos. Las crónicas hablan de la guerra con los grupos del interior. Dentro de la lógica de una sociedad guerrera, había otros elementos como secuestros y la toma de cabezas trofeos.

A pesar de la toma de hombres como esclavos, no parecen haber sido clases sociales. Aparentemente no había acceso diferenciado a los medios de producción. Los esclavos hacían el trabajo más pesado, pero comían del mismo plato que el amo y dormían en el mismo toldo mosquitero. También el esclavo podría casarse con una mujer de la comunidad. No había tributo, sino que los súbditos hacían la huerta del cacique y remaban su canoa. En el caso de los omaguas, había un reconocimiento público de la familia del cacique. En vez de hablar de sociedades basadas en clases sociales, el término más indicado sería sociedades basadas en rangos. Son sociedades donde no hay acceso desigual a los recursos, pero donde sí hay acceso desigual a posiciones estructurales y prestigio.

Estos cacicazgos tenían la necesidad de mantener algunas relaciones de intercambio con los grupos de la selva alta para obtener sal, e implementos de piedra, y jpyas de oro y plata. También los pueblos que vivían en las tierras no inundables habrían sido importantes como fuente de alimentos en los años cuando había inundaciones más grandes de lo normal o cuando las inundaciones llegaban cuando todavía los productos no estaban listos para cosechar. Actualmente se hace trueque, en estos casos, entre la llanura de inundación y la tierra firme, pescado por yuca.

No se debe subestimar la práctica del almacenaje de yuca ablandada en hoyos en la llanura de inundación. Generalmente las familias tienen alimentos disponibles durante las inundaciones. El momento crítico es la bajada del nivel del río hasta que puedan tener nuevas cosechas. En los siglos pasados, este alimento en la forma de fariña (yuca tostada) habría mantenido a la gente durante este período. Las tortugas acuáticas mantenidas en lugares no inundadas habrían proporcionado la proteína.

Las sociedades antiguas de la llanura de inundación mantenían ejércitos porque necesitaban no sólo las tierras inundables, sino también los lugares para pescar y cazar animales acuáticas, la recolección de hojas de palmeras para los techos de las casas y los frutos y muchos otros productos. Otra razón de proteger territorios grandes eran el cambio de los cursos de los ríos y la erosión, que obligaban a cambiar los lugares de cultivo.

Desde el siglo XIX, los cocamas, a demás de seguir en su territorio ancestral, han ocupado el nicho ecológico que dejó la desaparición de los mainas ribereños en la región del Marañón entre el Morona y el Pastaza y el bajo Pastaza. Los candoshis y shapras de la zona están más orientados hacia la caza en el bosque y la extracción 
de la madera. También los cocamas y ticunas ocupan una buena parte del territorio de los antiguos omaguas en Perú, Colombia y Brasil. Actualmente la subsistencia de los cocamas sigue siendo la pesca, la caza de animales acuáticos, la recolección de taricayas y sus huevos, y el cultivo de yuca y maíz entre otros productos.

Mucho de la cultura tupí sobrevive, a pesar de la desaparición de sus cacicazgos. Las causas del ocaso de estos cacicazgos fueron las enfermedades epidémicas que disminuyeron la población enormemente y el régimen de trabajo forzoso o esclavitud a que fueron sometidos los indígenas, llamado en el Perú «encomienda». Posteriormente fueron agrupados en misiones multiétnicas, aunque algunos mantenían el sistema de los caciques durante algún tiempo dentro de las misiones. Para conocer más a fondo la adaptación a las llanuras de inundación en cuanto a subsistencia, organización social y cosmovisión, son importantes los estudios que se hacen ahora sobre los cocamas, los shipibo-conibos y yines.

Bibliografía

ACOSTA, José de

1962 [original 1590] Historia Natural y Moral de las Indias. México: Fondo de Cultura Económica.

ACUÑA, Cristóbal

1986 [original 1639] «Descubrimiento del Amazonas». Informes de Jesuitas en la Amazonía, 1600-1684, Jaime Regan, compilador. Iquitos: CETA-IIAP.

AGÜERO, Oscar Alfredo

1992 The Millenium among the Tupi-Cocama: A Case of Religious Ethno-dynamism in the Peruvian Amazon. Uppsala Research Reports in Cultural Anthropology. Quito: Ediciones Abya Yala, Lima: CAAAP.

ARRIAGA, Pablo Joseph de

1974 «Carta al P. Claudio Aquaviva, Lima, 24 de agosto de 1597» Monumenta Peruana, tomo VI (1596-1599), Antonio de Egaña, editor. Romae: Institutum Historicum Societatis Iesu.

BENITES, Dorinethe dos Santos

2006 As Primeiras Imagens da Amazônia, Manaus: Centro Cultural dos Povos da Amazônia. 
CABRAL, Ana.

1995 Contact Induced Language Change in the Western Amazon: The Non Genetic Origen of the Kokama language, tesis doctoral. University of Pittsburg.

CARNEIRO, Robert L.

1970 «A Theory of the Origen of the State», Science 169: 733-738.

1981 «The Chiefdom: Precursor of the State». The Transition to Statehood in the New World. Edited by G. D. Jones and R. R. Kautz, pp. 37-79. Cambridge, UK New York, NY: Cam-bridge University Press.

1995 «The History of Ecological Interpretations of Amazonia: Does Roosevelt Have It Right?», Indigenous Peoples and the Future of Amazonia: An Ecological Anthropology of an Endangered World, Leslie E. Sponsel, editor, pp. 45-70. Tucson: The University of Arizona Press.

CARVAJAL, Gaspar de

1942 [original c. 1542] Relación del Nuevo Descubrmiento del Famoso Río Grande. Quito: Biblioteca Amazonas.

\section{CHANTRE Y HERRERA, José}

1901 [original c. 1770]. Historia de la Compañía de Jesús en el Marañón Español. Madrid: Imprenta de A. Avrial.

CHIBNIK, Michael

1994 Risky Rivers: The Economics and Politics of Floodplain Farming in Amazonia. Tucson: The University of Arizona Press.

CIEZA DE LEÓN, Pedro

1973 (original 1553) La Crónica del Perú. Lima: Ediciones Peisa.

COOK, Noble David

1998 Born to Die: Disease and New World Conquest, 1492-1650. Cambridge University Press.

DE LA CRUZ, Laureano

1999 [original 1653] Descripción de los Reynos del Perú con Particular Noticias de lo Hecho por los Franciscanos. PUCP / Banco Central de la Reserva del Perú.

DENEVAN, William M.

1980 «La Población aborigen de la Amazonía en 1492», Amazonía Peruana, 5: 341.Lima: CAAAP.

ENGEL, Frederic

1966 Paracas: Cien Siglos de Cultura Peruana. Lima: Editorial Juan Mejía Baca. 


\section{ESPINOSA, Lucas}

1935 Los Tupí del Oriente Peruano. Estudio Lingüístico y Etnográfico. Madrid: Imprenta de la Librería y Casa Editorial Hernando.

EVANS, Clifford and Betty MEGGERS

1968 Archeological Investigations on the Rio Napo, Eastern Ecuador. Washington: Smithsonian Institution Press.

FIGUEROA, Francisco de

1986 [original 1661] «Relación de las Misiones de la Compañía de Jesús en el País de los Maynas». Informes de Jesuitas en la Amazonía, 1600-1684, Jaime Regan, compilador. Iquitos: CETA-IIAP.

FRIED, Morton $\mathrm{H}$.

1967 The Evolution of Political Society: An Essay in Political Anthropology. New York: Random House.

FRITZ, Samuel

1988 «Diario de la Bajada del P. Samuel Fritz, misionero de la Corona de Castilla en el río Marañón, desde San Joachim de Omaguas hasta la Ciudad del Gran Para, por el Año de 1689, y vuelta del mismo Padre desde dicha Ciudad hasta el Pueblo de La Laguna, cabeza de las Misiones, por el Año de 1691, en Maroni.

GIRARD, Rafael

1958a «En Pos de los Misteriosos Omagua», en Indios Selváticos de la Amazonía Peruana, pp. 163-185. México: Libro Mex Editores.

1958b «Los Cocama», en Indios Selváticos de la Amazonía Peruana, pp. 187-197. México: Libro Mex Editores.

HURTADO GÓMEZ, Lina María

2007 «Elementos para Cuestionar la Pobreza y Marginalidad Urbanas en las Ciudades Amazónicas», Amazonia desde Adentro: Aportes a la Investigación de la Amazonía Colombiana, Valentina Nieto y Germán Palacio, editores, pp. 127152. Leticia: Universidad Nacional de Colombia.

IMBELLONI, José

1963 "Cephalic Deformations of the Indians in Argentina», Handbook of South American Indians, Julian Steward, editor, tomo 6, pp. 53-55. New York: Cooper Square Publishiers.

IIAP

2007 «Conclusiones», Seminario: Contribución a la Política Nacional de Desarrollo Sostenible de las 'Restingas' o 'Llanuras de Inundación' en la Amazonía. Iquitos: 
Instituto de Investigaciones de la Amazonía Peruana. www.iiap.org.pe/ Upload/restinga/11.doc

JIJÓN y CAAMAÑO, Jacinto

1997 Antropología Prehispánica del Ecuador, segunda edición. Quito: Museo Jacinto Jijón y Caamaño, Agencia Española de Cooperación Internacional.

JIMÉNEZ DE LA ESPADA, Marcos, editor

1965 [c. 1549-1619] Relaciones Geográficas de Indias, tomo III-IV. Madríd: Biblioteca de Autores Españoles.

JORNA, Peter

1991 «Vuelta a la historia: los Cambeba del Solimoes», Etnohistoria del Amazonas, P. Oorna, L. Malaver, M. Oostram coordinadores, pp-. 213-244. Quito: AbyaYala, MLAL.

LATHRAP, Donald

1970 The Upper Amazon. New York: Praeger.

LÓPEZ DE VELASCO, Juan

1971 Geografía y Descripción Universal de las Indias. Madrid: Biblioteca de Autores Españoles.

LUCERO, Lorenzo

1986 «Carta al P. Vice-Provincial Gaspar Vivas, escrita en Lagunas el 20 de mayo de 1681», Informes de Jesuitas en la Amazonía, 1600-1684, Jaime Regan, compilador, pp. 320-324. Iquitos: CETA-IIAP.

MAGNIN, Jean

1998 [original 1742] Descripción de la Provincia y Misiones de Mainas en el Reino de Quito. Quito: Biblioteca Ecuatoriana «Aurelio Espinosa Pólit» y Sociedad Ecuatoriana de Investigación Histórica y Geográfica.

MARONI, Pablo.

1988 [original 1738] Noticias Auténticas del Famoso Río Marañón, Jean-Pierre Chaumeil, compilador. Iquitos: CETA-IIAP.

MARTÍN CUESTA, José

1984 Jaén de Bracamoros, 5 tomos. Lima: Librería Studium.

MEGGERS, Betty

1971 Amazonia: Man and Culture in a Countereit Paradise. Chicago: Aldine-Atherton.

1981 Amazonia: Hombre y Cultura en un Paraíso Ilusorio. México: Siglo XXI Editores. 
MELIÀ, Bartomeu

1986 El Guaraní Conquistado y Reducido. Asunción: Universidad Católica

MELIÀ, Bartomeu, Georg Grünberg y Friedl Grünberg

2008 Pai-Tavyterã: Etnografia Guarani del Paraguay Contemporâneo, segunda edición. Asunción: Centro de Estudios Antropológicos de la Universidad Católica y Centro de Estudios Paraguayos «Antonio Guasch».

MERCADO, Pedro de

1957 Historia de la Provincia del Nuevo Reino y Quito de la Compañía de Jesús, 4 tomos. Bogotá: Biblioteca de la Presidencia de Colombia.

MÉTRAUX, Alfred

1927 «Les Migrations Historiques des Tupi-Guarani», Journal de la Société des Américanistes de Paris, tomo XIX.

1963 «Tribes of the Middle and Upper Amazon River», en Handbook of South American Indians, Julian Steward, editor, vol. 3. New York: Cooper Square Publishers.

1973 Religión y Magias de América del Sur. Madrid: Ediciones Aguilar.

1979 A Religiâo dos Tupinambás e suas Relações com a das demais Tribos Tupi-Guaraníes, segunda edición. Editora da Universidade de São Paulo.

MORA, Gilda

s.f. El Dorado Colombia. http://www.eldoradocolombia.com/ruta_con_ google_earth.html

MORALES CHOCANO, Daniel

2002 «Contactos entre Cocamas y Shipibos: Un Acercamiento Arqueológico en la Amazonía Peruana», Investigaciones Sociales, año VI, no. 10, pp. 47-70. Lima: UNMSM. Instituto de Investigaciones Históricosociales.

MYERS, Thomas

1988 El efecto de las pestes sobre las poblaciones de la Amazonía Alta», Amazonía Peruana, VIII (15:61-81).

1992 "The expansion and collapse of the Omagua», Journal of the Steward Anthropological Society, 20 (1-2).

NUNES, Diego

1993 [original 1551] Carta de Diego Nunes a D. João III de Portugal. As Crônicas do Rio Amazonas, Antonio Porro, editor. Petrópolis: Vozes.

ORTI, Guerra Toribio de

1968 (Original 1586) Jornada del Río Marañón. Madrid: Biblioteca de Autores Españoles. 


\section{PEÑA VENEGAS, Clara}

2003 «Sistematización de las Practicas de Conservación de Biomasa de Yuca (Manihot Esculenta), en la Varzea del Río Amazonas, Realizadas por los Indígenas Ticuna / Sur del Trapecio Amazónico». Leticia: Ministerio de Ambiente, Vivienda y Desarrollo Territorial.

RAVINES, Rogger

1990 «La Tiradera, propulsor o estólica en el antiguo Perú», Boletín de Lima, no. 70, pp. 29-34.

REGAN, Jaime

1983 Hacia la Tierra Sin Mal: La Religión del Pueblo en la Amazonía, $1^{\mathrm{a}}$ edición. Iquitos: CETA.

RIVAS RUIZ, Roxani

2003a Uwaruitata: Los Kukama-Kukamiria y su Bosque. Iquitos: WWF y FORMABIAP. 2003b «Aspectos de la Cosmovisión Kukama-Kukamiria», Amazonía Peruana, no. 2829. Lima: CAAAP.

2004 El Gran Pescador: Técnicas de pesca entre los cocama-cocamillas de la Amazonía Peruana. Lima: Pontificia Universidad Católica del Perú.

RODRÍGUEZ, Manuel

1990 [original 1684] El Descubrimiento del Marañón Madrid: Alianza Editorial.

ROOSEVELT, Anna Curtenius

1980 Parmana: Prehistoric Maize and Manioc Subsistence along the Amazon and Orinoco. New York: Academic Press

1987 "Chiefdoms in the Amazon and Orinoco», Chiefdoms in the Americas, Robert D. Drennan aand Carlos A. Uribe, editors, pp. 153-184. Lanham, Md.: University Press of America.

1991 Moundbuilders of the Amazon: Geophysical Archaeology on Marajó Island, Brazil.San Diego: Academic Press.

1993 El Apogeo y el Ocaso de los Señoríos de la Amazonía (traducción del inglés de Jaime Regan), en L'Homme, no. 126-128, pp. 255-283.

SAAVEDRA, Cristóbal de

1965 [original 1619] «Relación de la entrada que hizo el gobernador don Diego Vaca de Vega [...]», Relaciones Geográficas de Indias, tomo III-IV. Madríd: Biblioteca de Autores Españoles.

SALINAS LOYOLA, Juan de

1965 [original 1558]. «Descubrimientos, conquistas y poblaciones», Relaciones Geográficas de Indias, Marcos Jiménez de la Espada, editor, tomo IV. Madrid: Biblioteca de Autores Españoles. 
STOCKS, Anthony Wayne

1981 Los Nativos Invisibles: Notas sobre la Historia y Realidad Actual de los Cocamilla del Río Huallaga, Perú. Lima: CAAAP.

TAYLOR, Anne Christine

1988 Al Este de losAndes: Relaciones entre las Sociedades Amazónicas y Andinas entre los Siglos XV y XVII, F.M. Renard-Casevitz, Th. Saignes y A.C. Taylor, compiladores, tomo II. Quito: Ediciones Abya-Yala, Lima: Instituto Frances de Estudios Andinos

1999 «The Western Margin of Amazonia from the Esrly Sixteenth to the Early Nineteenth Century», The Cambridge History of the Native Peoples of the Americas: South America, Frank Salomon and Stuart B. Schwart, editores, vo. III, part 1 and 2, pp. 188-256. Cambridge University Press.

TAYLOR, Anne Christine y Cristóbal LANDÁZURI, Estudios y Compilación.

1994 Conquista de la Región Jívaro (1550-1650). Quito: Marka, Abya-Yala / Lima: IFEA.

TESSMANN, Günter

1999 [original 1930]. Los Indios del Noroeste Peruano. Quito: Ediciones Abya-Yala.

URIARTE, Manuel

Diario de un Misionero de Maynas. Iquitos: CETA.

VÁZQUEZ, Francisco de

1988 [original 1562] El Dorado: Crónica de la Expedición de Pedro de Ursúa y Lope de Aguirre. Madrid: Alianza Editorial.

VEIGL, Francisco Xavier

2006 [original 1789] Noticias Detalladas sobre el Estado de la Provincia de Maynas en América Meridional hasta el Año 1768. Iquitos: CETA.

VILLAREJO, Avencio

1988 Así es la Selva, cuarta edición. Iquitos: CETA.

WOODS, W.I. y J.M. McCANN

2001 «Origen y Persistencia de las Tierras Negras de la Amazonía», Desarrollo sostenible en la Amazonía ¿Mito o Realidad? Mario Hiraoka y Santiago Mari editores, pp. 23-30. Quito: Ediciones Abya Yala.

Mapa: Evans and Meggers 1968, p.94

Estólicas: Engel 1966, pp. 182, 184, 185

Cabezas chatas: Imbelloni 1963, p. 54

Calavera achatada: Daniel Morales

Fotos: Alexander Aquituari Ahuanari 


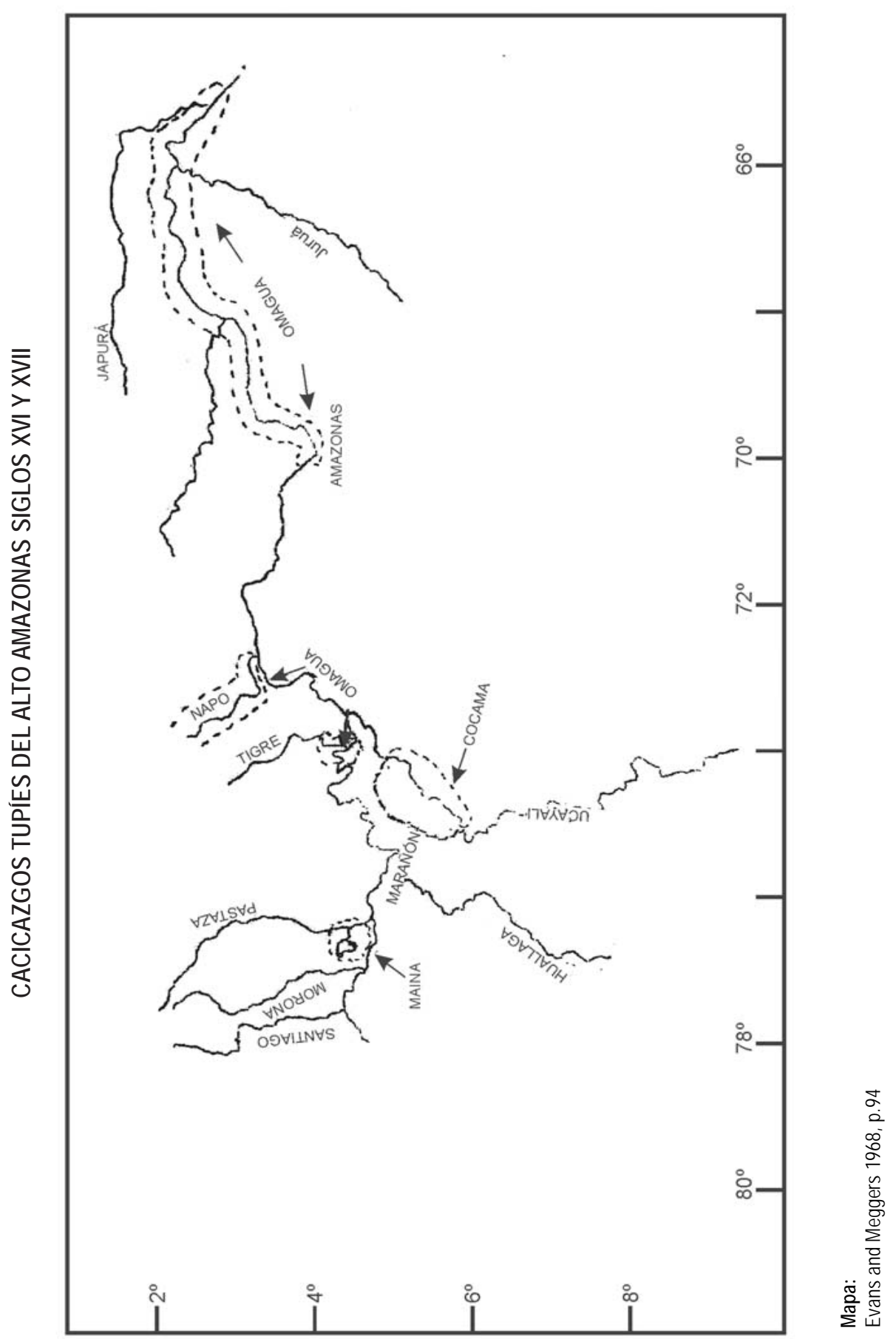



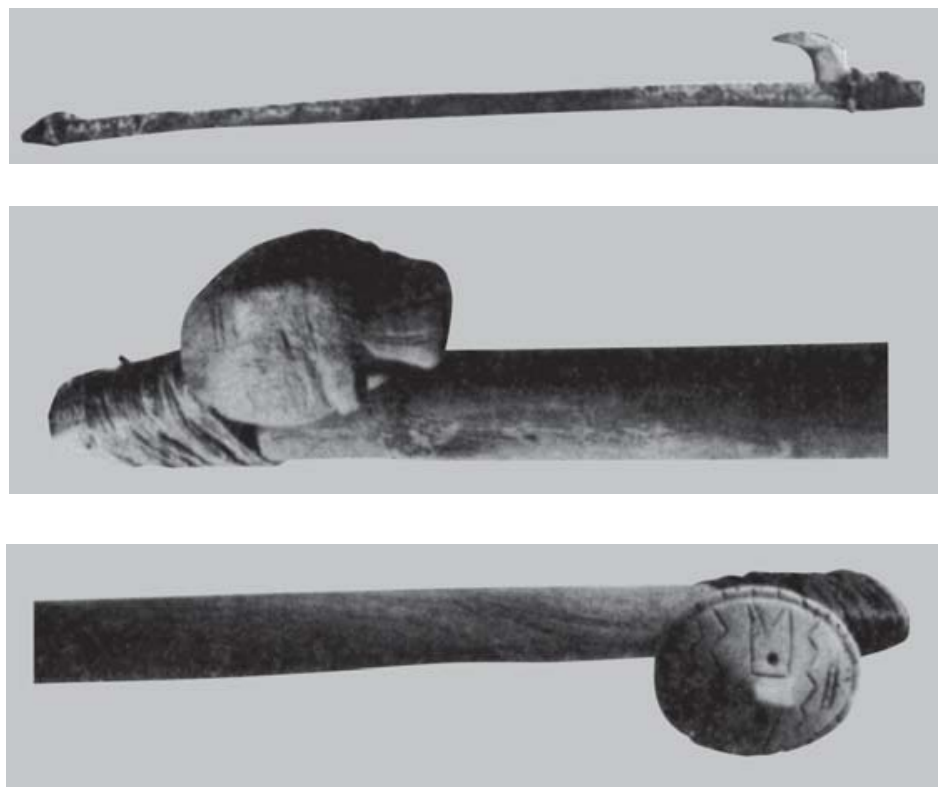

Estólicas:

Engel 1966, pp. 182, 184, 185

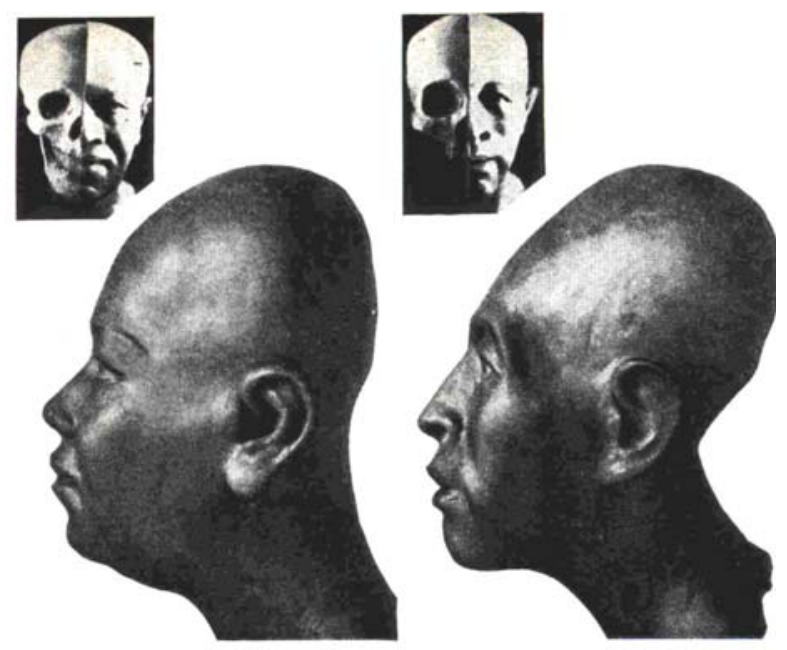

Cabezas chatas:

Imbelloni 1963, p. 54 


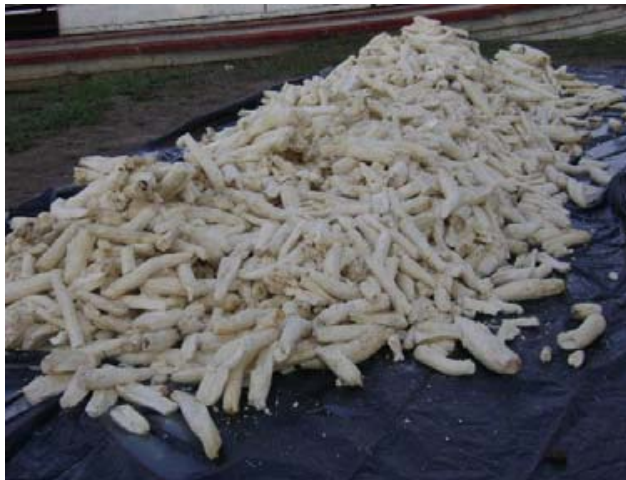

Yuca pelada para ablandar

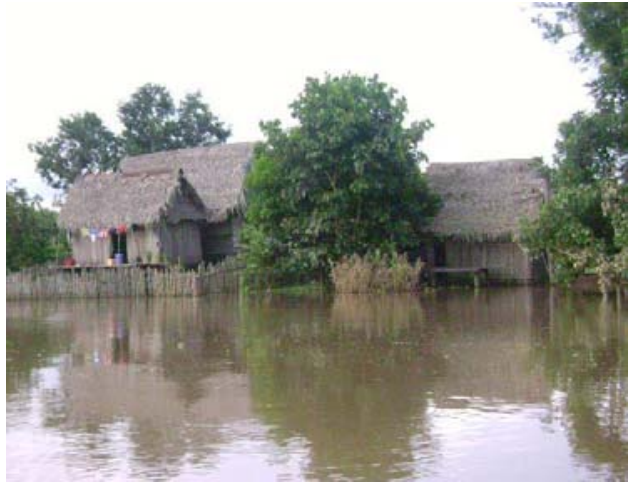

Casa kukama en llanura de inundación 1

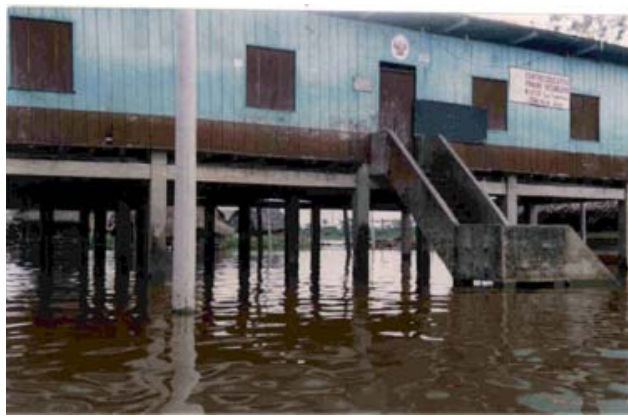

Escuela en barrio Belén, zona baja, Iquitos

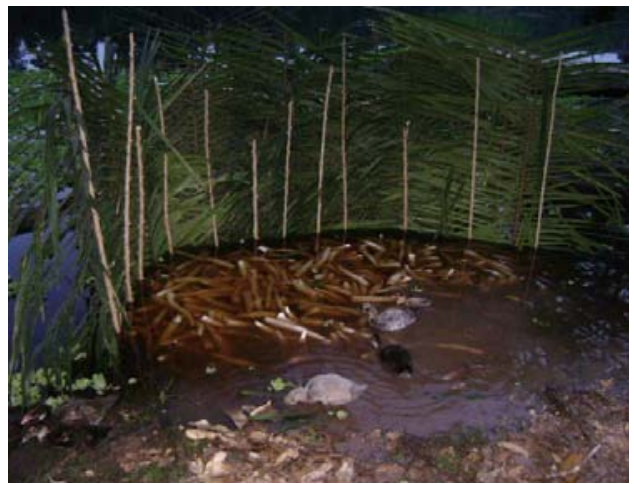

Yuca en proceso de ablandarse

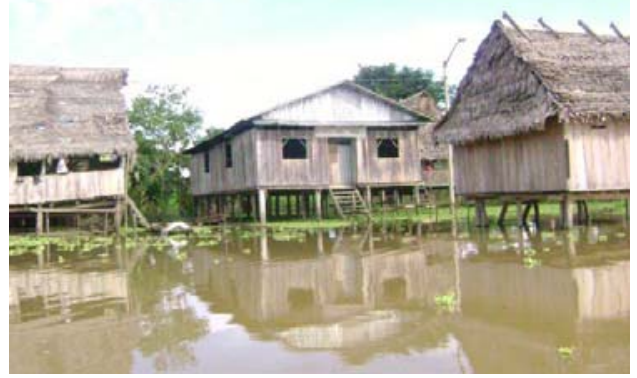

Casa kukama en llanura de inundación 2

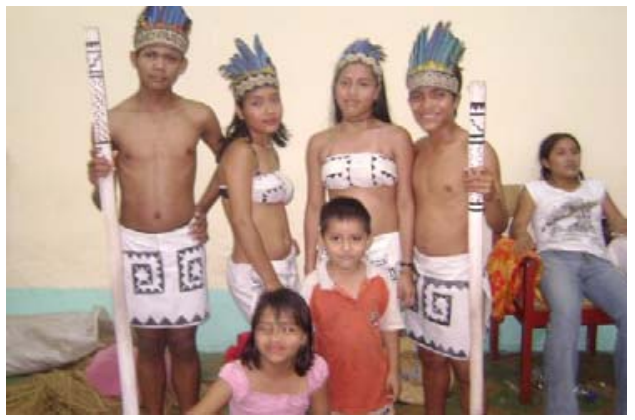

Grupo folklórico «Raíces kukamas»1 


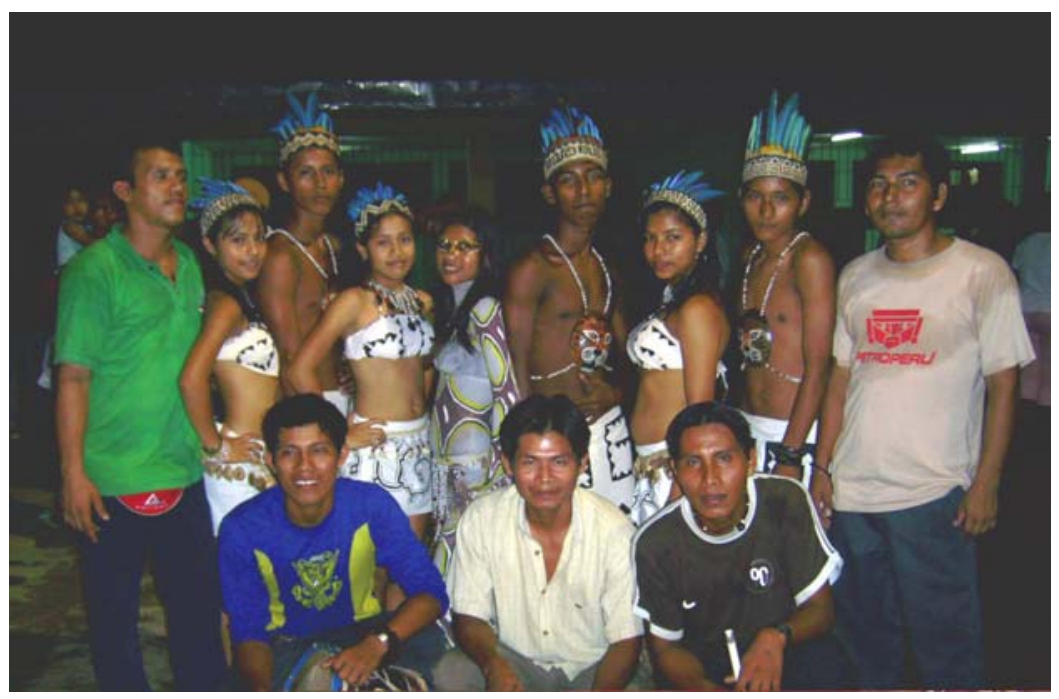

Grupo folklórico «Raíces kukamas» 2 